\title{
Ergebnisse von Abtragungsmessungen an periglazialen Solifluktionsschuttdecken in vier Hochgebirgen der Iberischen Halbinsel (Picos de Europa, Peña Prieta, Sierra de Urbión und Sierra Nevada)
}

\author{
KARL-UlRich Brosche*) \\ Meinen Eltern gewidmet
}

Actual movement of solifluction covers, quantification, experimental sites, influence of rock material, vegetation, height, slope inclination, humidity of experimental sites, snow cover, four high mountain regions, Spain

\begin{abstract}
Kurzfassung: In vier spanischen Hochgebirgen (Picos de Europa, Peña Prieta - Kantabrisches Gebirge, Sierra de Urbión - Nördliches Iberisches Randgebirge, Hauptmassiv der Sierra Nevada - Betische Kordillere) wurden insgesamt 33 Meßsfelder zur Ermittlung der Bewegungsgeschwindigkeit von Solifluktionsschuttdecken angelegt und über einen Zeitraum von 3 bis 4 Jahren meistens einmal jährlich vermessen (Tab. 1). Vermessene Steinmarkierungen und Holzpflöcke lieferten z. T. aussagekräftige Ergebnisse, die durchaus im Rahmen der Ergebnisse anderer Autoren liegen (Tab. 2). Der Einfluß der absoluten Höhe, der Vegetationshedeckung, der Hangneigung, der Exposition, der Durchfeuchtung des Materials und der Dauer der Schneedecke wurden berücksichtigt.
\end{abstract}

\section{[Results of measurements of solifluidal denudation processes in four recent periglacial high mountain areas of Spain (Picos de Europa, Peña Prieta, Sierra de Urbión and Sierra Nevada)]}

\begin{abstract}
In four Spanish high mountain areas (Picos de Europa, Peña Prieta - Cantabrian mountains, Sierra de Urbión - Northern Iberic border mountains, main massif of the Sierra Nevada) there were made investigations about the velocity of movement of solifluidal deposits. 33 experimental sites which were measured once every year or (in some cases) every two years over a period of three or four years brought about a lot of results (table 1 ) which are comparable with the results of other authors in other parts of the world (table 2). Methodically speaking, there were used both stakes of wood (with a length of $20 \mathrm{~cm}$ ) and painted rocks. The significance of height above sea level, vegetation cover, slope inclination, exposition, humidity, rock material, and duration of snow cover were considered.
\end{abstract}

\section{Einleitung}

Im Rahmen mehrjähriger periglazialmorphologischer Untersuchungen auf der Iberischen Halbinsel (BROSCHE 1971 a. u. b., 1972, 1974, 1978 a. u. b., 1983, 1986),

*) Anschrift des Verfassers: Prof. Dr. K.-U. Brosche, Institut f. Geographische Wissenschaften der FU Berlin, Fachrichtung Physische Geographie, Grunewaldstraße 35, 12165 Berlin die auf 53 Gebirge mit Höhen von mehr als 2000 m ausgedehnt worden sind, trat zwangsläufig die Frage nach einer quantitativen Erfassung der Abtragungsprozesse, besonders der Solifluktionsprozesse, in das Forschungsinteresse. Dieser Frage wurde systematisch seit 1971 nachgegangen, als mehr und mehr auch der vorzeitliche periglaziale Formenschatz, küstenmorphologische und bodengeographische Studien in das Forschungsprogramm aufgenommen wurden. Als besonders geeignet für quantitative Untersuchungen zu langsamen solifluidalen Massenbewegungen erwiesen sich die Picos de Europa (2648 m) im Kantabrischen Gebirge Nordspaniens, das Gebiet nördlich der Peña Prieta $(2531 \mathrm{~m})$ südlich der Picos de Europa, die Sierra de Urbión ( 2255 m) im nördlichen Iberischen Randgebirge und die Nord- und Südseite der Sierra Nevada $(3467 \mathrm{~m}$ ) im Süden Spaniens. Alle Gebirge sind nämlich entweder zu Fuß oder mit dem Auto gut zugänglich und ließen sich zu Nachmessungen relativ leicht erreichen, wobei allerdings z. T. auch weite Fußmärsche nötig waren.

In den Picos de Europa steht devonischer Massenkalk ("caliza de montaña") an, der ein lehmig-toniges Verwitterungssubstrat bis in Höhen von über $2400 \mathrm{~m}$ liefert, im nördlichen Vorland der Peña Prieta tritt überwiegend Tonschiefer und Phyllit an die Oberfläche, in der Sierra de Urbión steht als Schichtstufen-Sockelgestein Mergel, als Schichtstufenbildner kreidezeitlicher Sandstein an. In der Sierra Nevada dominieren Glimmerschiefer und Granatglimmerschiefer.

Es wurden in drei von vier Gebirgen (nicht in der Sierra de Urbión) Meßfelder bereits in der potentiellen bzw. realen Waldstufe angelegt. In den Picos de Europa installierten wir zwischen 1700 und $2400 \mathrm{~m}$ insgesamt 7 Meßfelder; in der Sierra Nevada wurden auf der N-Seite zwischen ca. 2300 und $3150 \mathrm{~m}$ fünf Meßfelder, auf der Südseite zwischen 1750 und ca. $3100 \mathrm{~m} 13$ Meßfelder eingerichtet.

Bis zum Beginn der 50er Jahre gab es neben einigen eher zufälligen Meßergebnissen noch keine genauen 
Vorstellungen über die Intensität periglazialer Massenverlagerungen. Forscher wie НӧGвом (1914), Poser (1932), Troll (1944), Peltier (1950), Jahn (1951) und DyLıK (1953) hoben die besondere Intensität der periglazialen Prozesse hervor, wobei POser (1932) schon früh auf die besondere Bedeutung der fluvialen Prozesse in rezenten Periglazialgebieten hinwies. НӧGвOм (1914, S. 369) schreibt z. B. zur Intensität der Solifluktion wörtlich: "Ich glaube ..., daß eine jährliche Verschiebung, die einige Zentimeter oder Dezimeter beträgt, als ziemlich mäßig betrachtet werden kann, aber wo sie einen oder einige Meter erreicht, daß die Geschwindigkeit groß ist." BǜDEL (1948) formulierte, ohne besonders auf die Bedeutung der Solifluktion einzugehen, in seinem Aufsatz über die klimamorphologischen Zonen der Polarländer: "Die Frostschuttzone zeigt daher unter allen klimamorphologischen Zonen der Erde die größte Abtragungsintensität." BüDEL (1948) äußerte diese Ansicht, wie oben angedeutet, zu einer Zeit, als noch keine systematischen Untersuchungen vorlagen. Vorher hatte DEGE (1941) in seiner Arbeit über "Landformende Vorgänge im eisfreien Gebiet Spitzbergens" berichtet, daß im August nach Regenfällen ein Schuttstrom an einem Hang in Bewegung gesetzt wurde und innerhalb von knapp drei Tagen maximal $9-19 \mathrm{~cm}$ verfrachtet wurde. Bei dieser Art der Verlagerung handelte es sich offenbar nicht um Gelifluktion im Sinne WASHBU RNs (1979), sondern um ein Durchtränkungsfließen i. S. SøRENsENs (1935), das nicht klimagebunden ist

Intensive Bemühungen um die quantitative Erfassung von Verwitterungs- und Abtragungsvorgängen in den rezenten Periglazialgebieten sind erst seit 1952 zu verzeichnen. Es seien hier vor allem Arbeiten von SIGAFOOS \& Hopkins (1952 - Alaska), von Williams (1957 Norwegen, 1966 - Kanada), RudBerg (1958 - 1964 Skandinavien), JAHN (1961) und BÜDEL (1961 - beide Spitzbergen), RAPP (1961 bis 1970 - Skandinavien), WASHBURN (1960, 1967, 1973, 1979 - Grönland) und HARRIS (1973, 1981) genannt. Ähnlich intensive Untersuchungen aus den Alpen liegen trotz einiger Vorarbeiten von Michaud (1950) und Michaud \& CAILlEuX (1950) erst seit 1972 mit Furrers (1972) Arbeit über "Bewegungsmessungen auf Solifluktionsschuttdecken" und mit STOCKERs (1973) Arbeit über Bewegungen auf Schrägterrassen in der Kreuzeckgruppe vor. Speziellen Problemen, nämlich der Kombination der Messung rezenter Bewegungen auf Solifluktionsloben mit Daten, die aus fossilen, ${ }^{14} \mathrm{C}$-datierten Böden unter großen Solifluktionsloben gewonnen wurden, woraus auch ihre Bewegung im Laufe des Holozäns erschlossen wurde, gingen seit 1966 BenEDICT (1966, 1976), Worsley \& Harris (1976), Alexander \& Price (1980), GAMPER (1981, 1982, 1983, 1985) und VeIT (1987) nach.

Den meines Wissens letzten zusammenfassenden
Überblick über laufende Feldmessungen zur Natur und zur Geschwindigkeit periglazialer Prozesse gibt French (1976), wobei alle Prozesse der studierten Objekte und alle benutzten Methoden tabellarisch aufgelistet (1976: Tab. 1) und die Projekte in Kurzform vorgestellt werden (Tab. 2).

Zur Iberischen Halbinsel liegen $\mathrm{m}$. W. noch keine Ergebnisse zur Messung der Abtragungsgeschwindigkeit in Solifluktionsschuttdecken vor, sieht man einmal von einigen kurzen Bemerkungen bei Brosche (1978 a und b, 1983) und bisher unveröffentlichten Ergebnissen von BROSCHE (1974) ab.

Es ist zu bemerken, daß fast alle hier zitierten Autoren ihre Untersuchungen in Permafrostgebieten durchgeführt haben, während die Meßfelder auf der Iberischen Halbinsel wahrscheinlich alle in Nichtpermafrostgebieten liegen.

Im Rahmen meiner Untersuchungen wurde folgenden, z. T. ineinander übergehenden Fragestellungen nachgegangen:

a) Gibt es bereits in der Waldstufe oder in Aufforstungsgebieten nahe der natürlichen Waldgrenze meßbare solifluidale Bodenverlagerungen?

b) Welche Bewegungsbeträge ergeben sich in für die jeweiligen Gebirge typischen Solifluktionsreliefs?

c) Läßt sich mit zunehmender Höhe und abnehmender Vegetation eine Zunahme der solifluidalen Massenverlagerungen feststellen?

d) Welche Feinbeobachtungen zu anderen Verlagerungsvorgängen und $\mathrm{zu}$ anderen als solifluidalen Prozessen lassen sich machen?

e) Sind die jährlichen Bewegungsbeträge etwa gleich, oder ergeben sich von Jahr zu Jahr deutliche Unterschiede?

f) Lassen sich Aussagen über die Rolle der Vegetation und die Bedeutung des Feuchtigkeitsangebots machen?

g) Werden oberflächennahe Steine schneller bewegt als bis in $20 \mathrm{~cm}$ Tiefe eingeschlagene Holzpflöcke?

h) Lassen sich Aussagen über die Rolle der Schneebedeckung und ihrer Dauer bei der Messung der Bewegungsgeschwindigkeit machen?

\section{Methodisches Vorgehen}

Die zwischen 1971 und 1975 durchgeführten Untersuchungen beinhalten die Messung der jährlich, z. T. jedoch in zwei Jahren erfolgten Bewegung von $20 \mathrm{~cm}$ langen Holzpflöcken ("stakes", "dowels"), die nach der Installation 1 - $2 \mathrm{~cm}$ aus dem Boden schauten, und die Bewegungsmessung von mit Farbe markierten Steinen. In manchen dafür geeigneten Meßfeldern wurden Pflöcke und Steine vermessen, in schuttigsteinigem Material nur Steine, in Rasengelände nur Pflöcke, zusätzlich in einem Falle auch noch Wanderblöcke.

Die Meßfelder wurden hangabwärts mit dem stärk- 
sten Gefälle etwa in einer Fluchtlinie angelegt und mit einem 30 bzw. $50 \mathrm{~m}$ langen Nirosta-Stahlmeßband vermessen. Der Ausdehnungskoeffizient für NirostaStahlmeßbänder beträgt $10,2 \times 10^{-6}$ bei Temperaturen zwischen $20^{\circ}$ und $50^{\circ}$. Da alle Messungen am Sommerbeginn bzw. im Hochsommer vorgenommen wurden, dürften keine Meßfehler gemacht worden sein, die mit dem Ausdehnungskoeffizienten zusammenhängen. Ausgewertet wurden nur die Messungen, die bei stramm angezogenem Meßband ermittelt wurden, ohne daß ein Stein oder ein Vegetationsbüschel das Meßband auf der Meßstrecke berührte. Windstille wurde bei der Messung immer abgewartet.

Auf Strukturbodenfeldern mit Miniaturstreifenböden wurden $10 \mathrm{~cm}$ lange Rundpflöcke installiert, deren Gebrauch sich im Gegensatz zu den $20 \mathrm{~cm}$ langen quadratischen Pflöcken als ungünstig erwies. Sie froren meistens nach einem Jahr so weit heraus, daß sie im folgenden Jahr bei der beabsichtigten Nachmessung umgekippt waren.

Als Markierungspunkte dienten in allen Fällen feste Felsausbisse. Quermeßfelder, wie sie z. B. WASHBURN $(1967,1979)$ in Grönland anlegte und von festen Punkten von der Seite her mit dem Theodolithen vermaß, wurden infolge einer meistens ungenügenden Geländesituation nicht angelegt.

Die Messungen wurden in der Regel im Abstand von ca. einem Jahr (11,5 bzw. 12,5 Monaten) durchgeführt, nie mehrmals in einem Jahr. Somit konnte nur der jährliche Bewegungsbetrag ermittelt werden; es konnten dagegen keine genaueren Detailstudien zu den einzelnen Prozessen wie "jump" ("frost caused creep" i. S. JAHNs 1961), "gelifluction" ("viscous flowage" i. S. JAHNs 1961) und "september movement" sowie "retrograde movement" (alles i. S. WASHBURNs 1967, 1979) durchgeführt werden. - Vor einer Nachmessung wurden die Holzpflöcke, die fast alle jährlich jeweils um ca. $2 \mathrm{~cm}$ aufgefroren waren, in ihr Loch zurückgedrückt.

Die $20 \mathrm{~cm}$ langen quadratischen Holzpflöcke erwiesen sich als gutes Instrument zur Messung der Bewegungsgeschwindigkeit. Allerdings wurden sie in einigen Meßfeldern (z. B. in der Sierra de Urbión) während meiner Abwesenheit - wahrscheinlich von Hirten - entfernt und vermutlich für Feuerungszwecke verwendet. Das hatte zur Folge, daß manche Meßfelder nach einem Jahr ganz "ausfielen" oder daß in mehreren Meßfeldern einige Pflock-Jahresmessungen "ausfielen" und häufig neue Pflöcke installiert werden mußten. So versteht sich die unterschiedliche Anzahl der Meßwerte in verschiedenen Jahren (Tab. 1).

Der Meßfehler läßt sich für die angewendete Methode nicht exakt ermitteln. Er wird aufgrund der unten aufgeführten Erfahrungen auf $\pm 0,5 \mathrm{~cm}$ geschätzt. Es fiel auf, daß in vielen Meßfeldern, in denen allgemein nur minimale Bewegungsbeträge vermutet und auch

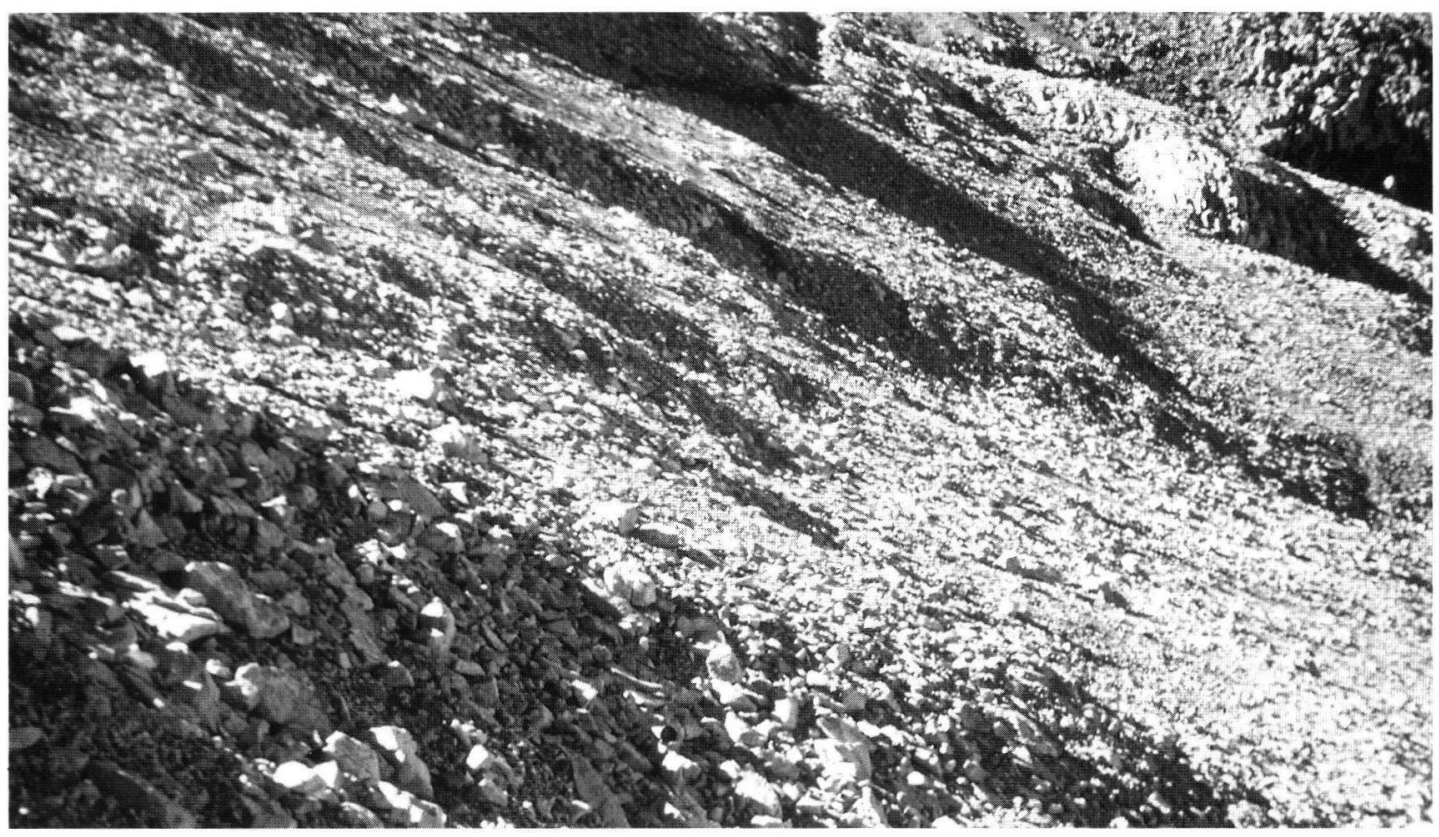

Abb. 1: Meßsfeld 3 in den Picos de Europa. Südfuß der Peña Vieja (südl. des Weges Refugio de Aliva zum Teleferico Fuente Dé). 1920 - 1930 m. Wanderblock mit Wulst und Negativform oberhalb des Blockes im geschlossenen Rasen. Tonschiefer unter Kalkwand. NNW-Exposition, $31^{\circ}$

Fig. 1: Experimental site 3 in the Picos de Europa. Southern foot of the Pena Vieja, south of the path from Refugio de Aliva to the Teleferico Fuente Dé. Height 1920 to 1930 m. "Wanderblock" with "Wulst" and niche upwards the bloc. Closed turf-vegetation, schists of marl under a chalk-wall. Exposition NNW, $31^{\circ}$ 
ermittelt wurden, viele Jahr für Jahr durchgeführte Messungen exakt den gleichen oder nur einen um wenige Millimeter differierenden Betrag ergaben. Es dürften also alle erzielten Werte nicht absolut exakte Werte sein - wie übrigens bei den Untersuchungen der Forscher vor WASHBURN (1967) ebenfalls nicht vgl. Tabelle 2 -, sondern wohl fundierte Tendenzen der Bewegungsgeschwindigkeit anzeigen.

An ausgewählten Beispielen wurden unter Annahme der Exaktheit der Meßergebnisse statistische Erhe- möglich war, ist die Anzahl der für den Gesamtjahresdurchschnitt der gesamten Meßreihe verwendeten Daten geringer als die Anzahl der Daten, die z. B. für eine einjährige Meßßreihe (1971/72) gewonnen wurden. Zusätzlich wurden die Minimal- und Maximalwerte vermerkt. Ebenso wurde in Tabelle 2 verfahren, sofern die einzelnen mit den gleichen Untersuchungen befaßten Autoren überhaupt neben Jahresmittelwerten Minimal- und Maximalwerte angeben. Problematisch bleibt in jedem Fall die Einbe-

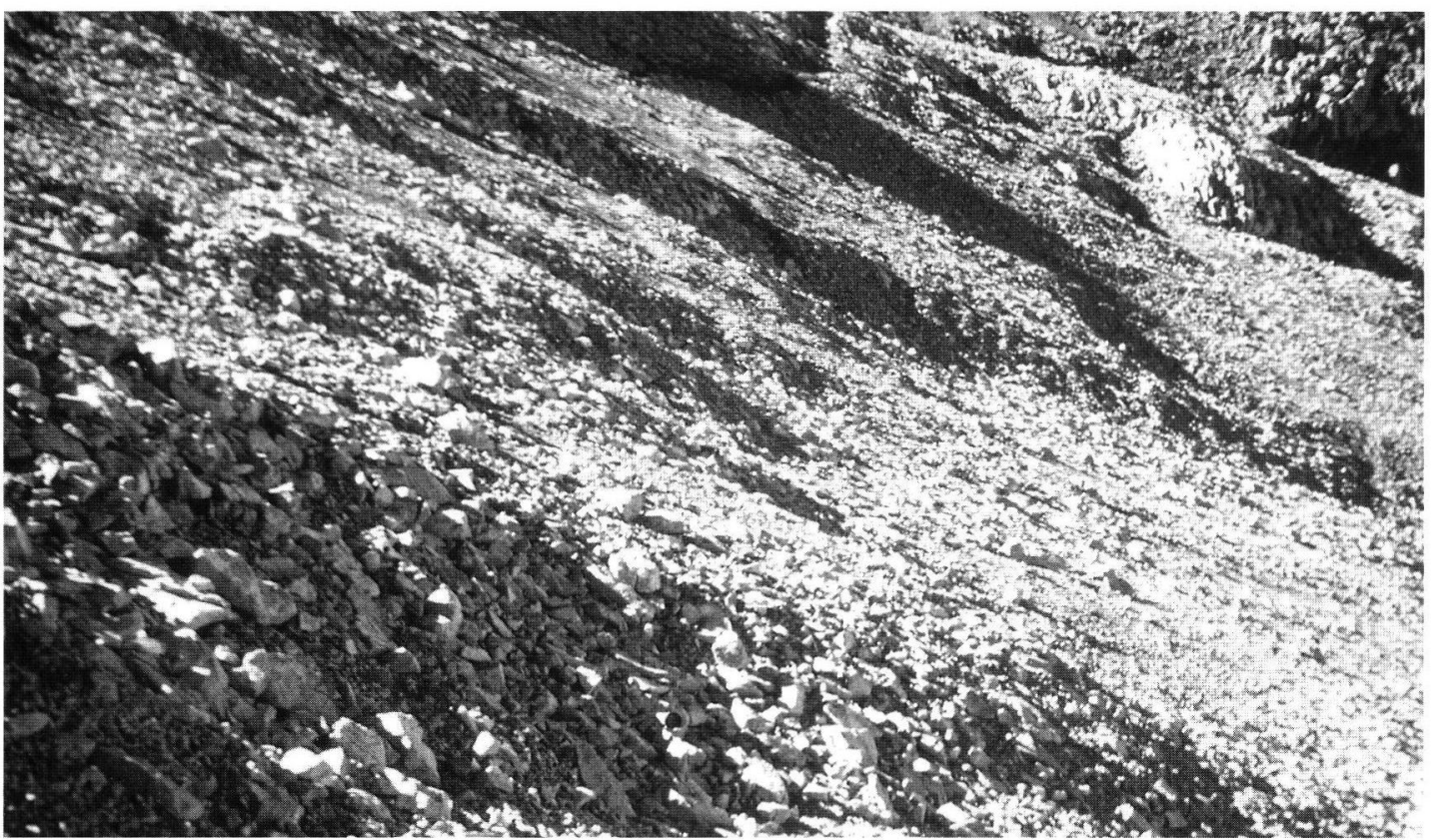

Abb. 2: Meßfeld 7 in den Picos de Europa. Südfuß der Bergkette Pico Tesorero (2570 m) - Torre Blanco (2551 m). Amorpher, ungebundener Wanderschutt aus "caliza de montana" bei $2400 \mathrm{~m}, 25$ - 28 $8^{\circ}$, S-Exposition. Der Wanderschutt, in eine lehmige braune Matrix eingebettet, fließt in Richtung auf eine Riesendoline.

Fig. 2: Experimental site 7 in the Picos de Europa. Southern foot of the mountain chaine Pico Tesorero (2570 m) - Torre Blanco $(2551 \mathrm{~m})$. Amorph solifluction layer without vegetation, formed by "caliza de montaña", height $2400 \mathrm{~m}$, inclination 25 - $28^{\circ}$, S-exposition. The solifluction layer, bedded into a loamy brown matrix, moves downslope to a big doline.

bungen nach dem T-Test unter Benutzung der 3-Sigma-Regel beim Mittelwertsvergleich zur Anwendung gebracht, um z. B. zu testen, ob sich in einem Mersfeld $18 \mathrm{~cm}$ tief eingeschlagene Holzpflöcke und oberflächlich "schwimmende" Steine, statistisch abgesi chert, unterschiedlich oder gleich schnell bewegen. Ebenso wurde in ausgewählten Vergleichen ermittelt, ob zwischen den einzelnen Mittelwertsergebnissen der Meßreihen signifikante Unterschiede im Sinne der Anwendung der 3-Sigma-Regel vorliegen. In Tabelle 1 wurden die Mittelwerte für ein oder/und zwei Jahre und die jährlichen Mittelwerte für die ganze dreioder vierjährige Meßreihe eingetragen; hierfür wurden nur die Meßergebnisse verwendet, die bei der jährlichen oder zweijährigen Nachmessung ermittelt wurden und durchgehend Werte ergaben. Da dies bei etlichen Pflöcken, weil sie verschwunden waren, nicht ziehung von sogenannten "Ausreißern". Das sind beispielsweise in einem Meßfeld mit einem Jahresdurchschnittswert von $1,46 \mathrm{~cm} / \mathrm{Jahr}$ Einzelwerte von 0,5 bis $0,6 \mathrm{~m}$. Diese wurden nicht für die Errechnung der Mittelwerte verwendet, da von ihnen angenommen werden muß, daß sie durch den Einfluß von Gemsentritt, durch Abspülung oder durch menschlichen Fußtritt, durch den ein Gleiten ausgelöst wurde verursacht wurden. Einige problematische Fälle von "Ausreißern" wurden in Tabelle 1 vermerkt.

Zum Schluß muß noch bemerkt werden, daß die eigenen Meßfelder sehr wahrscheinlich alle in permafrostlosen Gebieten liegen; für die höchsten Meßfelder in Höhen um 2900 - 3100 m über NN in der Sierra Nevada ist dies allerdings noch nicht ganz sicher. Beim Vergleich von Meßergebnissen im Kapitel 4 wird das jeweils zu berücksichtigen sein. 


\section{Ergebnisse von drei- bzw. vierjährigen Meßreihen in den Picos de Europa, in der Peña Prieta, in der Sierra de Urbión und in der Sierra Nevada}

\subsection{Picos de Europa (Nördliches Kantabrisches Gebirge)}

Hier wurden im Zentralmassiv Meßfelder zwischen 1700 m Höhe (100 m südlich des Paradors "Refugio de Aliva") und $2400 \mathrm{~m}$ Höhe (Südfuß des Tesorero 2570 m, Top. Karte v. Spanien 1:50 000, Bl. 80 Buronju, Spezialkarte Picos de Europa, Macízo Central) angelegt. Die Hangwinkel differieren auf den einzelnen Feldern nur zwischen $25^{\circ}$ und $32^{\circ}$. Die Meßfelder 1 - 4 befinden sich, zwischen $1700 \mathrm{~m}$ und $1940 \mathrm{~m}$ Höhe über NN, im Bereich geschlossenen oder fast geschlossenen Rasens und sind gut mit einem geländegängigen Fahrzeug erreichbar. Kalk, Tonschiefer und Kalk oder Tonschiefer allein bilden in diesen Meßfeldern ein tonig-lehmiges Verwitterungssubstrat, in das häufig Kalkblöcke eingebettet sind. Ein deutlicher Formenschatz der gebundenen Solifluktion tritt hier aber nicht auf, sieht man einmal von einigen Wanderblöcken (Abb. 1) in den beiden oberen Feldern (Merfeld 3 und 4) dieser vegetationsbestandenen Stu$\mathrm{fe} a \mathrm{~b}$. Die Messungen in diesen vier Feldern mit Rasenbedeckung ergaben, daß hier durchaus schon mit flächenhaften Massenverlagerungen zu rechnen ist einige Holzpflöcke zeigten jährliche Bewegungen von 2.5 bis $3,6 \mathrm{~cm}$. Da diese Gebiete beweidet werden, ist es nicht ausgeschlossen, daß Viehtritt (Pferde, Rinder, Ziegen, Schafe) diese recht großen jährlichen Wanderungsbeträge hervorgerufen hat. Die jährlichen Durchschnittswerte in den vier Merffeldern sind jedoch, wenn die ganze dreijährige Meßperiode betrachtet wird, noch relativ gering $(0,34 \mathrm{~cm} ; 0,32 \mathrm{~cm}$; $0,21 \mathrm{~cm} ; 0,85 \mathrm{~cm})$. Der höchste Wert von $0,85 \mathrm{~cm} / \mathrm{Jahr}$ wurde im offenbar recht fließfähigen Tonschiefer ermittelt (Meßfeld 4). Ein Vergleich der Meßfelder 3 und 4 ergibt, daß bei sonst nahezu gleichen sonstigen Faktoren offenbar der Gesteinseinfluß (Tonschiefer und Kalk zu Tonschiefer) durchschlägt.

Wie schon in Kapitel 2 in allgemeiner Form angedeutet, kam es in den Meßfeldern 3 und 4 zu größeren Ausfällen von Holzpflöcken.

Die Meßfelder 5 bis 7 liegen am S-Fuß des Tesorero (2570 m) im "caliza de montaña" (devonischer Massenkalk) bei ca. $2400 \mathrm{~m}$ Höhe im Höhenstockwerk der ungebundenen Solifluktion (Scherbenkarst); sie können erst nach einem längeren Fußmarsch erreicht werden. Die Hänge sind ungegliederte Solifluktionshänge (Abb. 2), in denen an Kleinformen höchstens Wanderungsstaublöcke (i. S. HölLermanns 1964) vorkommen. Der "caliza de montaña" liefert einen quellund rutschfähigen rotbraunen Verwitterungslehm, auf dem die Steine geradezu "schwimmen". In den Meß- feldern 5 und 7 wurden markierte Steine und Holzpflöcke vermessen, im Meßfeld 6 nur Steine. Bei Südexposition variieren die Hangneigungen zwischen $25^{\circ}$ und $28^{\circ}$. Der Schutt fließt in allen drei Fällen in Richtung auf große Dolinen ("hoyos") zu, die auf einem recht breiten Sattelgelände zwischen zwei Talsystemen liegen. Vom Mesfeld 6 abgesehen, ergeben sich in der Frostschuttzone des Scherbenkarstes deutlich höhere jährliche Bewegungsbeträge als im Rasengelände 700 bis $350 \mathrm{~m}$ tiefer (Meßfelder 1 - 4). Ein Vergleich der Ergebnisse von Meßfeld 4 (Meßreihe 1972 - 1975 - Pflöcke) mit denen von Merfeld 7 (Meßreihe 1971 - 1975 - Pflöcke) ergibt einen signifikanten Unterschied. Allerdings sind diese beiden Meßreihen streng genommen nicht vergleichbar, da sie nicht über den gleichen Zeitraum hin Ergebnisse lieferten.

Das Meßsfeld 7 konnte im Jahre 1972 nicht nachgemessen werden, da es am 25.7.1972 noch unter Schnee lag. Vergleicht man die Ergebnisse für Steinbewegungen der Meßfelder $5(1,88 \mathrm{~cm} / \mathrm{Jahr})$ und 7 $(1,60 \mathrm{~cm} / \mathrm{Jahr}) \mathrm{mit}$ den Ergebnissen der Pflockbewegungen in den Meßfeldern 1 - 4, so ergeben sich eindeutige signifikante Unterschiede. Die ungebundene Solifluktion, von Bünel (1948) auch freie Solifluktion genannt - wobei beide Bezeichnungen $\mathrm{m}$. E. in gleicher Weise unglücklich bzw. irreführend sind -, geht offenbar schneller vonstatten als die gebundene Solifluktion. Nach den neuen Ergebnissen von GAMPER (1983, 1985) kann dies jedoch nur mit Vorbehalt gesagt werden, denn in meinen Untersuchungen konnte die Rolle, die die Schneedeckendauer spielt, nicht untersucht werden. Sehr wahrscheinlich ist jedoch, daß die niedrigen durchschnittlichen Bewegungsbeträge in Meßfeld 6 auf die hier vorliegende Tendenz zu einer langanhaltenden Schneedecke im Vergleich zu den Meßfeldern 5 und 7 zurückzuführen ist. So konnten im Jahre 1972 bei der ersten Nachmessung nur die Pflöcke 1 - 7 nachgemessen werden, die in der Nähe der Wärme schnell aufnehmenden und reflektierenden hellen Felsen gelegen waren, während ab Pflock 8 das ganze Meßfeld noch unter einer Schneedecke lag. Das bestätigt die generellen Ergebnisse von GAMPER (1983, 1985).

Die Frage, ob sich $18 \mathrm{~cm}$ tief eingeschlagene Holzpflöcke schneller bewegen als oberflächlich "schwimmende" (also in das lehmige Verwitterungssubstrat schwach eingelagerte) Steine und kleine Blöcke läßt sich folgendermaßen beantworten: Der T-Test für das Meßfeld 6 hat ergeben, daß sich die Holzpflöcke $(0,25$ $\mathrm{cm} / J a h r)$ gegenüber den markierten Steinen $(0,62$ $\mathrm{cm} / \mathrm{Jahr})$ in signifikanter Weise weniger schnell bewegten und somit die Massenverlagerung in ca. 20 $\mathrm{cm}$ Tiefe bereits auf dem offenbar schneereichen Meßfeld weniger intensiv ist. Der Vergleich der Bewegungsgeschwindigkeit der Holzpflöcke (1,33 cm/Jahr) und Steine $(1,60 \mathrm{~cm} / \mathrm{Jahr})$ im Meßfeld 7 ergab dage- 
gen, daß kein signifikanter Bewegungsunterschied in diesem offenbar lange Zeit schneefreien, insgesamt gesehen mobileren Meßfeld vorliegt.

\subsection{Gebiet nördlich der Peña Prieta (Faro Robadorio und Alto de Cubil de Can) im Kantabrischen Gebirge}

Das Gebiet liegt auf Blatt 81 Potes der spanischen topographischen Karte 1:50 000 und ist über einen längeren Fußmarsch vom Dorfe Llanaves de la Reina aus, das an der Straße Riaño - Panes liegt, erreichbar. Das Meßfeld 8 liegt westlich des Passes zwischen Faro Robadorio (2192 m) und dem Berg Alto de Cubil de Can (2407 m) in 1800 - 1830 m Höhe (Abb. 3). Wie Abb. 3 erahnen läßt, läge hier ohne Beweidung durch tentiellen montanen Stufe bereits flächenhafter Bodenversatz auf $12-15^{\circ}$ geneigten Tonschieferhängen nachgewiesen werden kann. Das scheint mit den Durchschnittswerten von $0,85 \mathrm{~cm}$ (für 1972 - 1973) bzw. mit dem Durchschnittswert von $0,14 \mathrm{~cm}$ für die Periode 1973 - 1975 zumindest zeitweilig der Fall zu sein. Bei diesem Formenschatz in NW-Exposition und der völlig geschlossenen Rasendecke in der Umgebung wird allerdings noch keine untere Solifluktionsgrenze angesetzt, sondern erst bei einem flächenhaft entwickelten, viel deutlicheren Formenschatz, wie er in Abb. 5 und bei Brosche (1978 a, 32 ff. u. Abb. 8 - 17) dokumentiert ist.

Das in Abb. 4 sichtbare Rasengirlandenfeld am Rande eines Tälchens entspricht dem Meßfeld 9 und liegt zwischen 2050 und $2080 \mathrm{~m}$. ü. M., also ca. $250 \mathrm{~m}$ höher

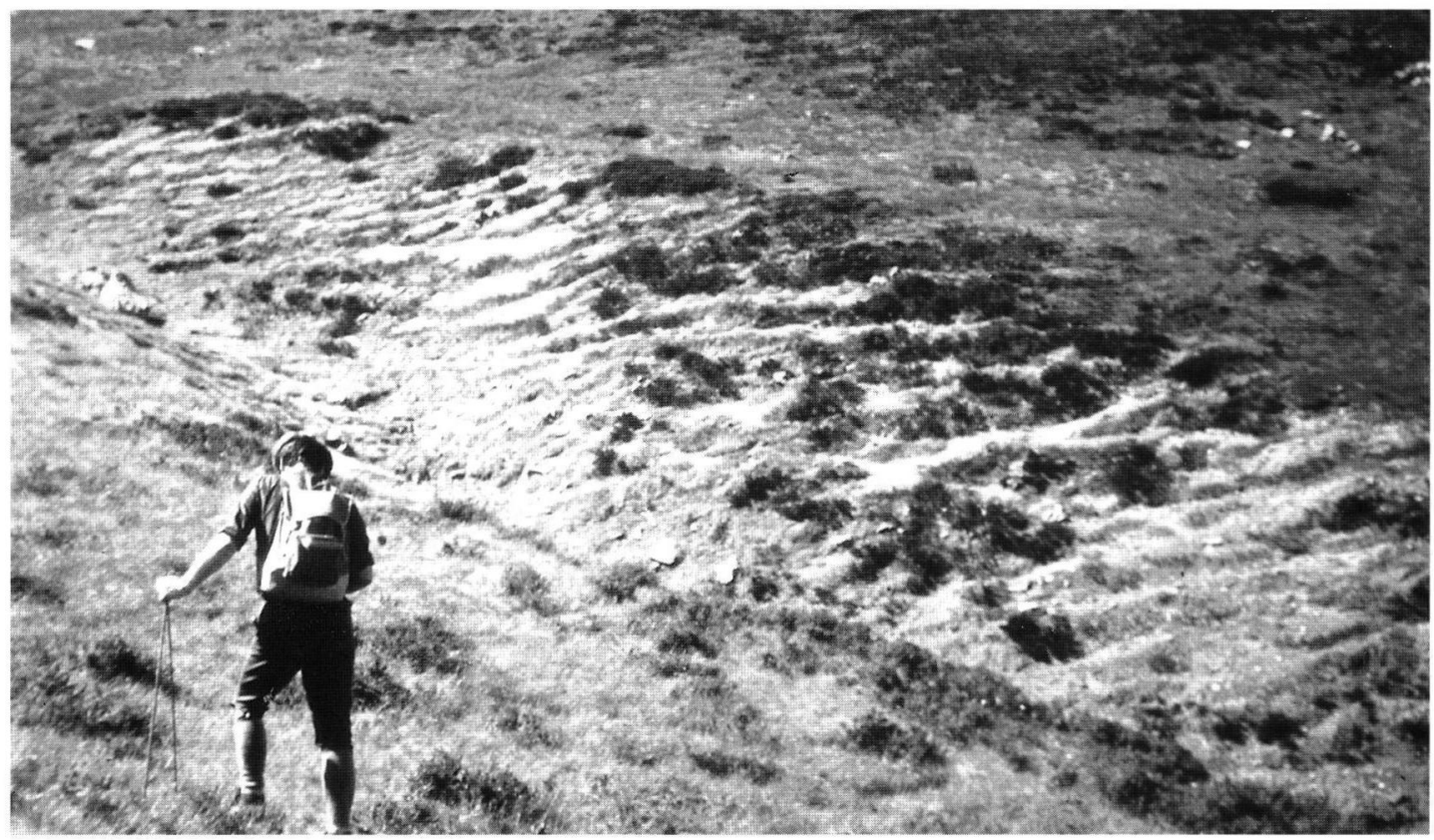

Abb. 3: Von Viehtritt in Stufen aufgelöste Rasendecke in einem Tälchen westlich des Passes zwischen Faro Robadorio (2192 m) und Alto de Cubil de Can $(2407$ m) im Peña Prieta-Gebiet (südl. der Picos de Europa). Stufen z. T. zu Rasengirlanden weiterentwickelt. 1800 - $1830 \mathrm{~m}$, Tonschiefer, 12 - 15², NW-Exposition (Meffeld 8).

Fig. 3: Turf cover put into steps by the influence of cattle in a little valley west of the pass between Faro Robadorio $(2192 \mathrm{~m})$ and Alto de Cubil de Can $(2407 \mathrm{~m})$ in the Peña Pricta region (south of the Picos de Europa, Northern Spain, Cantabrian Mountains). Steps partly formed to guirlands of turf ("Rasengirlanden"), height 1800 - $1830 \mathrm{~m}$, schists of marl, inclination $12-15^{\circ}$, NW-exposition, experimental site 8 .

Kühe und Kleinvieh wahrscheinlich eine geschlossene Rasendecke vor, zu deren Auflösung in Stufen wahrscheinlich der Viehtritt beigetragen hat. Das läßt sich u. a. auch aus dem Minimalwert von $-1,0 \mathrm{~cm}$ für den Zeitraum von 1973 bis 1975 und dem Maximalwert von $+3,5 \mathrm{~cm}$ für den gleichen Zeitraum wahrscheinlich machen. Bei beiden Werten dürfte Viehtritteinfluß mitgewirkt haben. Bei diesem Meßfeld sollte lediglich getestet werden, ob 150 - $200 \mathrm{~m}$ unterhalb der rezenten Solifluktionsgrenze in der oberen po- als das zuvor behandelte Meßfeld. Meßfeld 9 weist auch im Tonschiefergestein, allerdings in SW-Exposition entwickelt, bei deutlich größserer Hangneigung ( $25^{\circ}$ gegenüber $12-15^{\circ}$ bei Meßfeld 8 ) deutlich ausgedehntere Rasengirlandenvorkommen auf. Der Paß zwischen Faro Robadorio (links oben außerhalb der Abb. 4 gelegen) und Alto de Cubil de Can, $2407 \mathrm{~m}$ (rechts oben außerhalb der Abb. 4 gelegen), liegt in Fortsetzung des Tälchens in hangaufwärtiger Richtung. Die Hypothese lautete, daß das höhere Meß- 


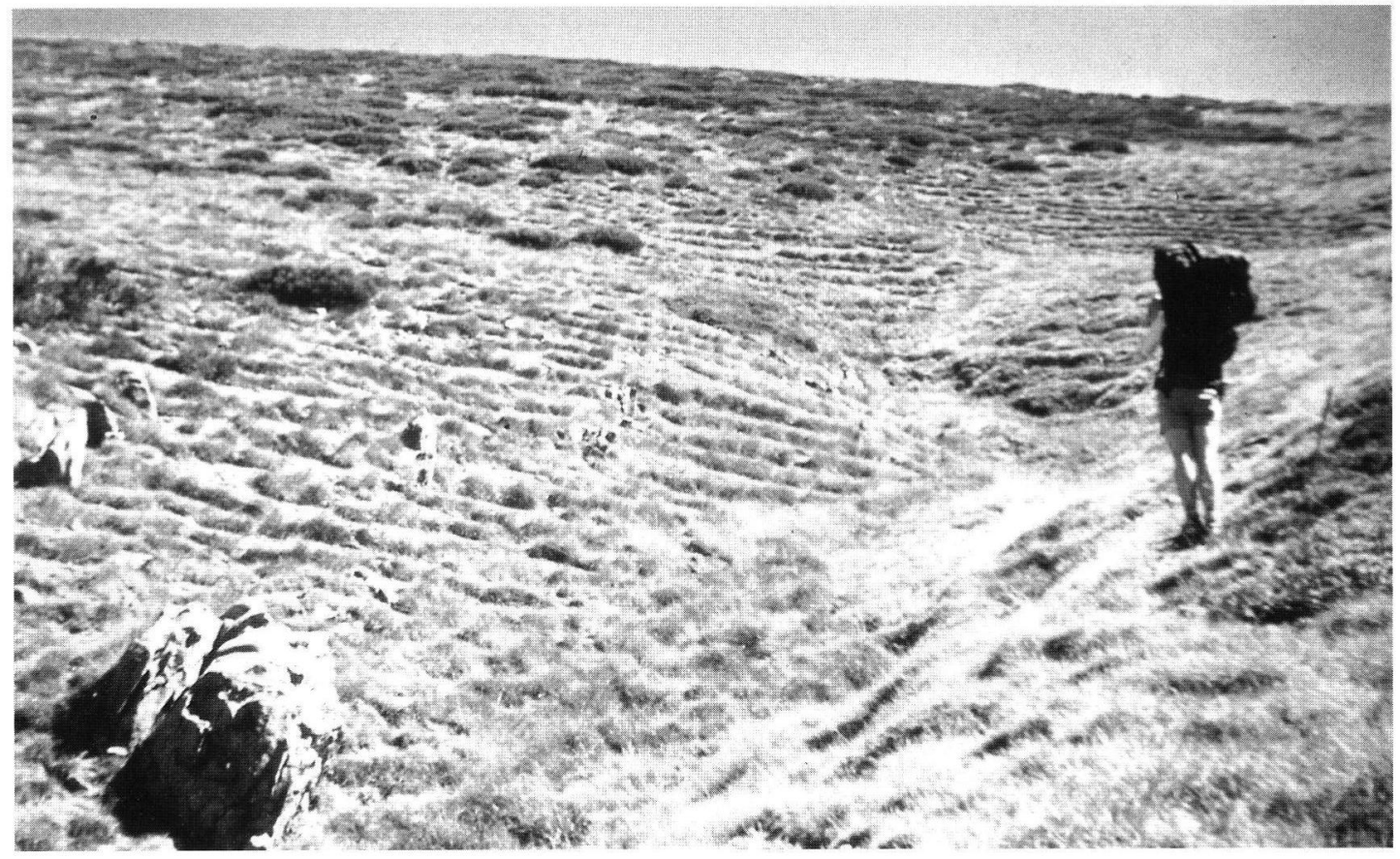

Abb. 4: Rasengirlanden der gehemmten Solifluktion bei 2050 - $2080 \mathrm{~m}$ am Rande eines Tälchens. Gleiche Lokalität wie Abb. 3. Tonschiefer, $25^{\circ}$, SW-Exposition (Merfeld 9).

Fig. 4: Turf guirlands ("Rasengirlanden") of the "gehemmte" solifluction in a height of 2050 - $2080 \mathrm{~m}$ at the ridge of a

little valley. Same locality as in Fig. 3. Schists of marl, inclination 25\%, SW-exposition (experimental site 9).

feld 9 mit seiner viel flächenhafteren Entwicklung von Rasengirlanden der gehemmten Solifluktion deutlichere Bewegungsbeträge als das Merfeld 8 aufweisen müsse, zumal es ca. $250 \mathrm{~m}$ höher liegt als Meßfeld 8. Diese Hypothese wird durch die Meßergebnisse bestätigt. Im Zeitraum 1972/73 wurde hier bei 11 Messungen an Holzpflöcken ein Durchschnittsbewegungswert von $1,48 \mathrm{~cm} / \mathrm{Jahr}$ ermittelt, für den Zeitraum von 1973 bis 1975 (2 Pflöcke waren zwischen 1973 und 1975 verschwunden) wurde ein Durchschnittsbewegungswert von $0,52 \mathrm{~cm}$ ermittelt. Auch hier also wieder ein relativ hoher Wert im Zeitraum $1972 / 73$ (1,48 cm/Jahr) wie bei Merfeld $8(0,85 \mathrm{~cm})$ und ein relativ niedriger jährlicher Wert für 1973 - 1975 $(0,52 \mathrm{~cm} / \mathrm{Jahr})$ wie im Meßfeld $8(0,14 \mathrm{~cm})$. Falls man dies nicht auf Intensitätsunterschiede in der Beweidung oder qualitative Unterschiede (mehr Schaf- und Ziegenbeweidung gegenüber 1972/73 mehr Rinderbeweidung) zurückführen muß, wozu keine Erhebungen angestellt wurden, müßte der Schluß gezogen werden, daß Intensitätsunterschiede in der Bewegungsgeschwindigkeit in verschiedenen Zeiträumen - 1972/73 einerseits, 1973-75 andererseits - vorliegen.

Die übrigen 4 Meßfelder (Meßfeld 10 - 13) dieses Gebietes wurden auf einem flach geneigten Rückengelände zwischen dem niedrigen nördlich gelegenen Berg Faro Robadorio (2192 m) und dem stattlich hohen Berg Alto de Cubil de Can (2407 m - vgl. Abb. 7 -
14 bei Brosche 1978 a, 32 ff.) angelegt.

Das im Glimmerschiefer entwickelte Paßgelände liegt fast gleich hoch (zwischen 2130 und $2150 \mathrm{~m}$ ) und ist überwiegend flach geneigt $\left(3-6^{\circ}\right)$. Nur das Meßfeld 13 weist $12-15^{\circ}$ Hangneigung auf. Aufgrund der Beweidung, der windausgesetzten Rückenlage und der bereits beträchtlichen Höhe ist das Gebiet nur noch sporadisch von Vegetation bestanden, so daß sich ein Formenschatz der gehemmten Solifluktion mit Rasengirlanden vom Miniaturtyp und von geraden Rasenstufen und girlandenförmig durchgebogenen Rasenstufen vom Mesotyp oder Makrotyp ergibt (vgl. Brosche 1978 a, Abb. 8, 9, 10, 11).

Zwischen der paramoartigen Polstervegetation, die aus festuca-Gräsern, Zwergwacholder und Zwergkieferrelikten besteht, treten große Flächen ohne Vegetation auf (Abb. 5), auf denen der Fein- und Grobschutt fast "frei" wandert (Abb. 13 und 14 bei BROSCHE 1978 a). Hier waren einmal heute kaum erkennbare Grobschutt-Feinschuttstreifen entwickelt, die durch Viehtritt zerstört sind. Bei Entfernung des oberflächlich auflagernden Schuttes kommt jedoch in der Feinerde ein Waschbrettmuster zum Vorschein (vgl. Brosche 1978 a, Abb. 15, Fig. 2 und 3). Die GrobschuttFeinschuttstreifen lassen eine Feinerde- und Schuttwanderung vermuten. Diese läßt sich auch bereits daraus ablesen, daß sich der Grobschutt vor den hangabwärts gelegenen Vegetationsbändern an Schuttstufen (Abb. 5 rechte Seite) ansammelt, was sich 


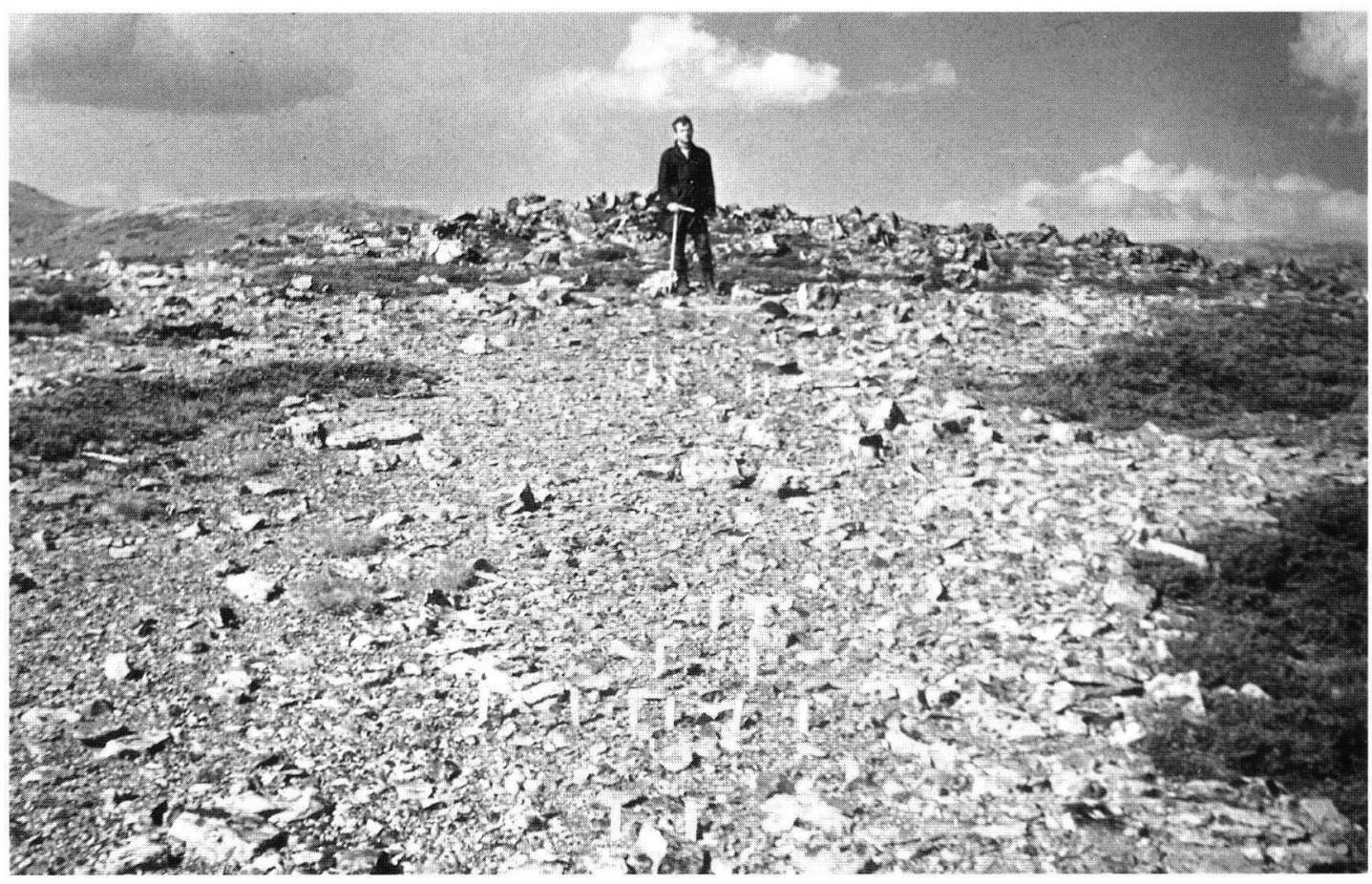

Abb. 5: Paßgelände zwischen Faro Robadorio $(2192 \mathrm{~m}$ ) und Alto de Cubil de Can (2407 m). Schuttfelder zwischen Mesostufen der gehemmten Solifluktion. $2130 \mathrm{~m}$, Glimmerschiefer, $5^{\circ}$, N-Exposition (Meßfeld 10). Bewegung erfolgt von links oben nach rechts unten.

Fig. 5: Pass region between Faro Robadorio $(2192 \mathrm{~m})$ and Alto de Cubil de Can (2407 m). Waste fields between "Mesostufen" of the "gehemmte" solifluction. $2130 \mathrm{~m}$, schists of glimmer, inclination $5^{\circ}$, N-exposition (experimental site 10). The movement of waste and loam takes place from the upper left part to the lower right part.

nur durch ein relativ schnelleres Wandern des Grobschutts auf dem tonig-erdigen Basismaterial (vgl. auch Abb. 10 u. 11 bei BROsche 1978 a) erklären läßt.

In fast allen Meßfeldern und in allen zeitlichen Perioden wurden auf diesen Schuttfeldern zwischen den Vegetationsbändern deutlich meßbare Bodenbewegungsbeträge gemessen. Es zeigt sich - wie in den Picos de Europa in Lagen von über $2400 \mathrm{~m}$ im Bereich der ungebundenen Solifluktion (Meßfelder 5 - 7) - die Tendenz, daß sich auf dem Feinmaterial "schwimmende" Steine im Meßfeld 11 offenbar schneller bewegen als bis in Tiefen von ca. $18 \mathrm{~cm}$ hineingetriebene Holzpflöcke.

Als Problem tauchten mehrere sogenannte "Ausreißer" auf (Meßfeld 11 und 13), die einen deutlichen Einfluß auf den Mittelwert ausüben können. Wegen dieser "Ausreißer" wurde auf statistische Berechnungen verzichtet, die bestimmte Mittelwerte als signifikant unterschiedlich zu anderen ausweisen würden (vgl. Tabelle 1 , Fußnoten 1 bis 3).

Allgemein läßt sich am Beispiel des Meßfeldes 11 zeigen, daß die Bewegungsbeträge nicht in jedem Jahr gleich hoch sind. Diese Aussage ist jedoch dahingehend einzuschränken, daß die alljährlich erfolgten Nachmessungen nicht in jedem Jahr exakt zur glei- chen Zeit erfolgt sind (vgl. Kapitel 2). So kann in einem Jahr die Nachmessung recht früh erfolgt sein, nachdem die Schneedecke gerade abgetaut war, der Boden noch gefroren war und somit kaum Massenbewegungen bis in $15-20 \mathrm{~cm}$ Tiefe erfolgen konnten.

Im Meßsfeld 13 scheint der geringe Bewegungsbetrag $(0,27 \mathrm{~cm}$ bzw. 0,08) im Zeitraum zwischen 1973 bis 1975 erfolgt zu sein gegenüber höheren Bewegungsbeträgen im Jahresrhythmus 1972/73 (0,6 bzw. 0,85 cm) - hier vermessene Holzpflöcke.

Die Hangneigungsunterschiede (Vergleich der Meßfelder 10 bis 12 - 3 bis $6^{\circ}$ - mit Merfeld 13 - 12 bis $15^{\circ}$ ) scheinen sich nicht auf die Intensität der durchschnittlichen Bewegungsbeträge auszuwirken. Angesichts der Gleichförmigkeit der Meßfelder - gemessen wurden im wesentlichen die Bewegungen in den Schuttfeldern zwischen den schmalen und breiteren Vegetationsbändern - überrascht es nicht, daß sich trotz der Expositionsunterschiede keine wesentlichen allgemeingültigen Aussagen machen lassen. Es erscheint allerdings voll berechtigt, diese Rückenflächen zwischen Faro Robadorio und Alto de Cubil de Can zur Solifluktionszone zu rechnen (BRosche 1978 a, S. 32 - 43). 


\section{Art d. Meß punkte Holz- pflöcke Steine \\ Zeitraum de
Messungen}

\section{Picos de Europa}

Refugio Aliva

2. Ost-Fuß der Peña Vieja

1700-1710 Kalk 32. SE gebunden

1790-1800 Kalk u. Tonschiefer

$25-28^{\circ}$ ENE

gebunden

$\mathrm{x}$

Süd-Fuß der 1920-1930 Kalk u. Tonschiefer

\section{$31^{\circ} \quad \mathrm{NNW}$} Peña Vieja Tonschiefer 29-30 NNW

Süd-Fuß der Peña Vieja

Fuß Tesorero/ 2380

Torre Blanco

6. Fuß Tesorero/ 2380 Kalk

Torre Blanco

Kalk

$25^{\circ} \mathrm{S}$

$5-28^{\circ} \quad S$

Fuß Tesorero/ 2400

Torre Blanco

Kalk

$25-28^{\circ} \quad S$

ungebunden

$\mathrm{x}$

Zahl der

Messungen

Durch- Bemerkungen Minimal- Maximal-

n

1972-1975

1972-1973

1973-1975

$1972-1973$

$1972-1975$

1973-1975

1972-1973

1973-1975

1972-1975

1972-1973

1972-1975

x 1972-1975

x 1972-1973

1971-1975

1971-1975

\begin{tabular}{cc}
$\mathrm{x}$ & $1971-1975$ \\
\hline $\mathrm{x}$ & $1973-1975$
\end{tabular}

1971-1975

1971-1975

gebunclen $x$

Westl. Paß am 1800-1830 Ton-

Faro Robadorio

schiefer

$12-15^{\circ}$ NW gebunden $\begin{aligned} & x \\ & x\end{aligned}$

Westl. Paß am 2050-2080 Ton-

Faro Robadorio

schiefer

25 SW gehemmt $x$

Südl. Faro 2130

Robadorio

Glimmer-

schiefer

$5 \quad N$

Südl. Faro

2150

Glimmer- $\quad 5,5-6^{\prime \prime} \quad \mathrm{S}$

Robadorio

schiefer

Glimmer- 3' WNW ungebunden $x$

schiefer

gehemmt

Glimmer-
schiefer

$12-15^{\circ} \mathrm{N}$

Südl. Faro

2150
1972-1973

1973-1975

1972-1973

$\begin{array}{rrr} & 1972-1973 & 8 \\ & 1973-1975 & 10 \\ & & \\ 1972-1973 & 11 \\ 1973-1975 & 9 \\ & & \\ & 1972-1973 & 11 \\ 1973-1975 & 11 \\ & & \\ & & 9 \\ & 1971-1972 & 26 \\ 1971-1972 & 26 \\ 1972-1973 & 26 \\ x & 1971-1975 & 20 \\ 1971-1972 & \\ & & 21 \\ & 1972-1973 & 17 \\ & 1972-1975 & 22 \\ 1972-1973 & 18\end{array}$

11

11

9
26

26

20

21
17
22
18

${ }^{12}$ Mit einem "Ausreißer", ohne diesen "Ausreißer": 0,48 cm; ${ }^{27}$ Mit einem "Ausreißer"; 


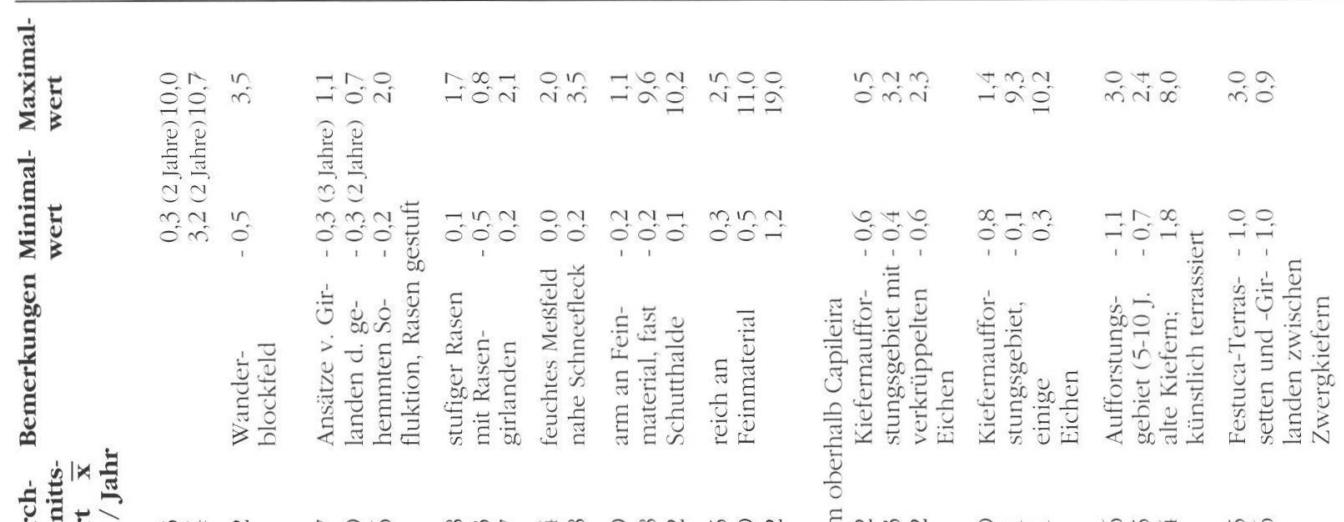

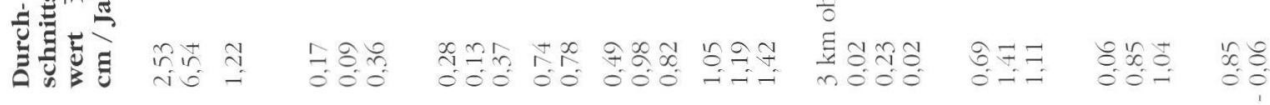

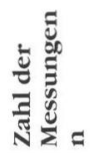

$\infty$ in 0

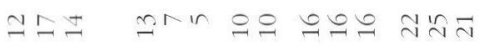

ํํำำ

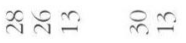

范

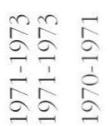

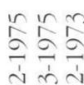

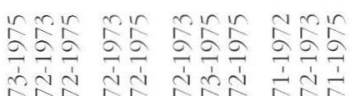

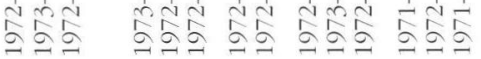

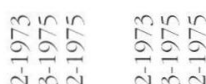

चें यें चें दे

×

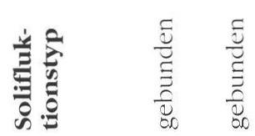

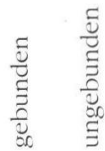

$\underset{\Xi}{\stackrel{\Xi}{\Xi}}$

芩

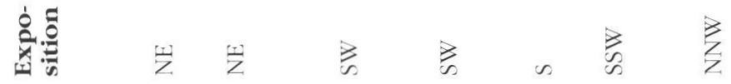

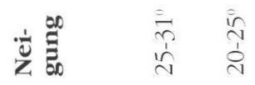

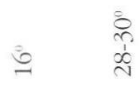

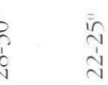

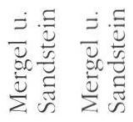

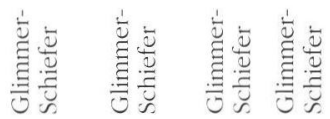

岂茪

竞莺

离苛离

产苛

离苞

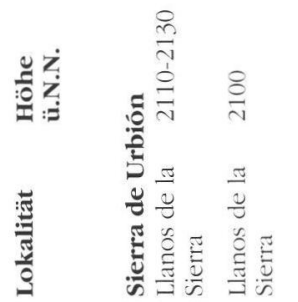

苟

$\dot{\Xi}$

苞

$\stackrel{4}{\frac{1}{7}}$

ầ

:

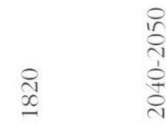

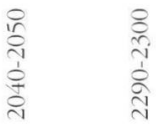

믐

$\pm \quad$ in

$\div$

$\stackrel{\infty}{2} \stackrel{2}{2}$

ते

$\overrightarrow{\mathrm{N}}$

กิ่

ชุ

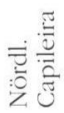

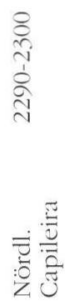

$\stackrel{+}{4}$ 


\section{Meßfeld Lokalität}

Nr.

Höhe

Gestein

ü.N.N.

Nei- Expo- Solifluk-

gung sition tionstyp

2400-2410 GlimmerSchiefer

Capileira

26. Nördl.
Capileira

27. Nördl.

Capileira

$28 . \quad$ Nördl.

Capileira westl. El

Chorillo

29. El Chorillo

2460

Glimmer-

Schiefer

$15^{\prime \prime}$, z.T. SSW

2465

Glimmer-

Schiefer

$16-17^{\prime} \mathrm{S}$

gehemmt,z.T. x

ungebunden $x$

2720-2730 Glimmer-

Schiefer

6. E

ungebunden

(vorwiegend) $\mathrm{x}$

gehemnt,z.T.

Glimmer-

Schiefer

$18-19^{\prime \prime}$

$\mathrm{x}$

30

S-Seite des

2950

Mulhacen

31

W-Seite des 3055

Mulhacen

W-Seite des

3060

Mulhacen

Glimmer-
Schiefer

Granat-

Glimmer-

Schiefer

Granat-

Schiefer

Glimmer-

$\mathrm{x}$

ungebunden

$27^{\prime \prime} \quad$ SSE ungebunden Schiefer

ungebunden

Art d. Meß

punkte

Holz- Steine

pflöke

e

$1972-1973$
$1972-1975$

Zeitraum de
Messungen

Zahl der

Messungen

Durch- Bemerkungen Minimal- Maximal-

\section{n}

14

14

$1972-1973$

$1972-1975$

1971-1972

$1972-1973$
$1971-1975$

1972-1975

1972-1975

$1971-1972$

1971-1975

$1971-1972$

1971-1975

$18^{\prime \prime} \mathrm{S}$

1971-1972

1971-1975

1971-1972

$1971-1975$

1972-1975

1972-1973

1972-1975

1972-1973 


\subsection{Sierra de Urbión}

Die Bergwelt der Sierra de Urbión ist von Covaleda (nordwestl. der Provinzhauptstadt Soria gelegen) über Forstwege gut mit dem Auto zu erreichen (Top. Karte v. Spanien 1:50 000, Blatt 316 Quintanar de la Sierra). Die Sierra de Urbión gehört zum nördlichen Iberischen Randgebirge und wurde bei Brosche (1978 a, 60 - 62, Abb. 25, 26) ausführlich behandelt und abgebildet. Eine an der Vorder- und Rückseite glazial überprägte mächtige Sandsteinschichtstufe bzw. ein Sandsteinschichtkamm, bestehend aus Mergeln im Sockelbildner und mächtigen, z. B. bankigen Sandsteinen im Stufenbildner - oberhalb der Waldgrenze gelegen - weist einen lebhaften Formenschatz der gebundenen Solifluktion auf. Dies gilt besonders für die steile Vorderseite, weniger für die flach $\left(8-15^{\circ}\right)$ abfallende Rückseite. An den windausgesetzten Rückenlagen dagegen ist die Vegetation aufgelockert, und ein Formenschatz der gehemmten Solifluktion stellt sich hier häufig ein. Abb. 6 gibt einen guten Eindruck von der rasenbewachsenen Vorderseite der Schichtstufe, an der neben Solifluktionszungen, -halbzungen, Loben und Schrägterrassen der gebundenen So- lifluktion auch riesige Wanderblöcke vorkommen, die vermessen wurden. Wenn in der Einleitung (Kap. 2) von Holzpflöcken die Rede war, die vermutlich von Hirten entfernt worden sind, so bezogen sich die Bemerkungen vor allem auf dieses Gebiet. Nicht auszuschließen ist allerdings auch, daß die Holzpflöcke von Rasenstraten innerhalb eines Jahres "überflossen" und damit verdeckt worden sind (s. u.). Obwohl hier ursprünglich in mehreren Meßfeldern mehrere hundert Holzpflöcke installiert und vermessen worden waren, konnten nur ganz wenige (5 Exemplare - Meßfeld 14) über einen Zeitraum von 2 Jahren 1971 bis 73 nach gemessen werden. Die Ergebnisse mit einem Durchschnittswert von $6,54 \mathrm{~cm} / \mathrm{Jahr}$ entsprechen der Vermutung, daß an diesem Hang bei 25 bis $31^{\circ}$ Neigung ein intensives Fließen vorliegt. Dabei kann es sich allerdings um eine Kombination von Gelisolifluktion und Durchtränkungsfließen handeln, denn bei NEExposition hält sich hier der Schnee bis lange in den Sommer und liefert reichlich Schneeschmelzwasser. Eindeutige Wanderungsbeträge wiesen hier auch die Wanderblöcke von einer Größe auf, wie sie in Abb. $1 \mathrm{zu}$ sehen ist. Da sie viel tiefer in den lehmig-tonigsteinigen Untergrund hineinreichen als die instal-

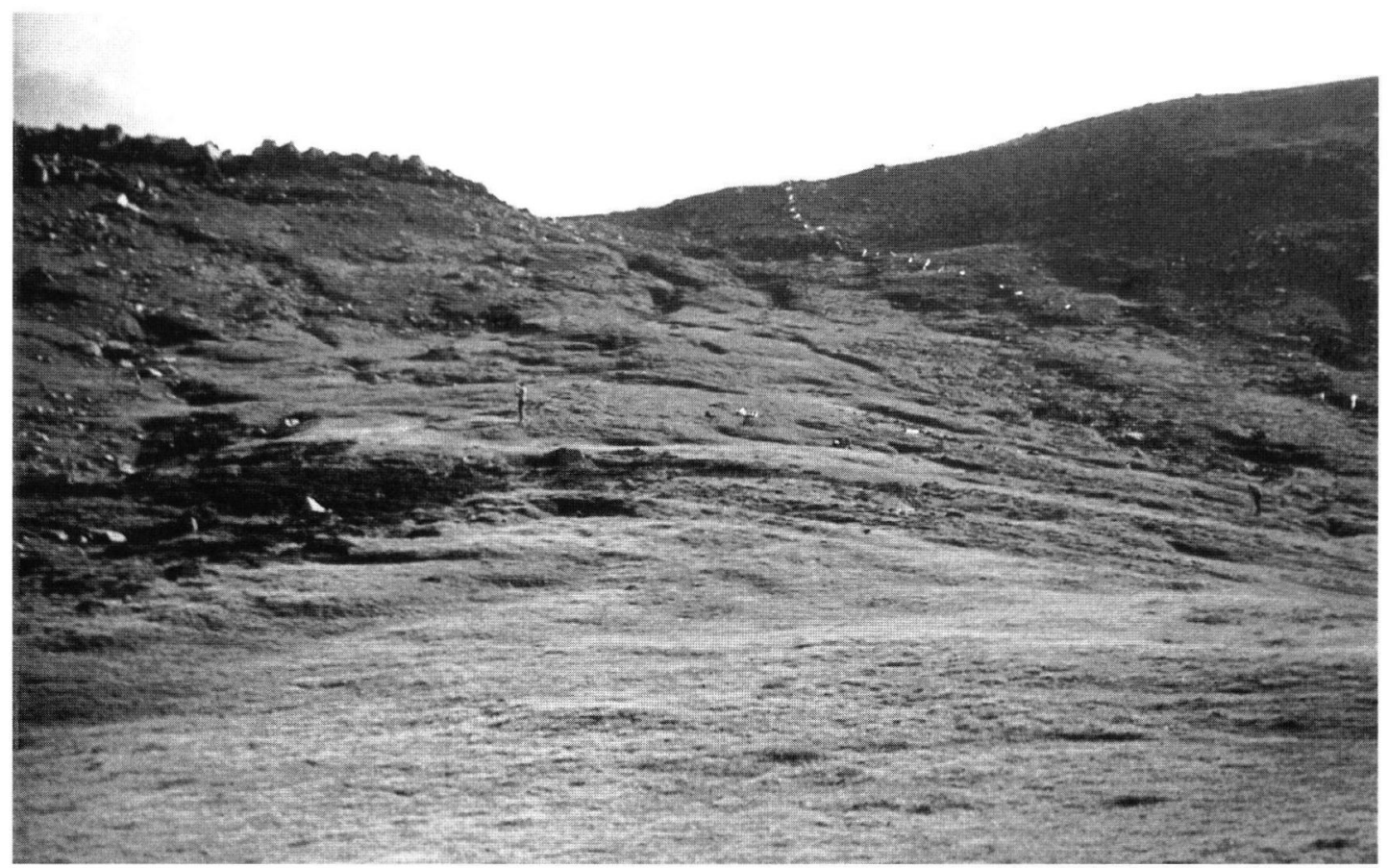

Abb. 6: NE-Seite der Llanos de la Sierra $(2183 \mathrm{~m})$ in der Sierra de Urbión (westl. Soria, nördliches Iberisches Randgebirge). Ab ca. $2030 \mathrm{~m}$ im Sandsteinschutt und roten Mergel (Mergel stellt Sockelbildner einer Sandstein-Schichtstufe) ein lebhafter Formenschatz der gebundenen Solifluktion mit Solifluktionsloben, Halbzungen und Schrägstufen. Im oberen Teil 25 $31^{\circ}$, NE-Exposition (Meßfelder 14 und 15).

Fig. 6: NE side of the Llanos de la Sierra $(2183 \mathrm{~m})$ in the Sierra de Urbión (west of Soria, northern Iberic ridge mountains - Nördliches Iberisches Randgebirge). Above $2030 \mathrm{~m}$ in sandstone waste and red marl vivid forms of the "gebundene Solifluktion" with solifluction lobes, "Halbzungen" (halftongues) and "Schrägstufen" (oblique steps). In the upper part $25-31^{\circ}$, NE-exposition (experimental sites 14 and 15 ). 
lierten Holzpflöcke, erfahren sie offenbar eine nicht so schnelle Bewegung wie die sich an der Hangoberfläche recht schnell bewegenden Straten aus rasenbestandenem lehmigem Material. An steileren Hängen von 25 bis $31^{\circ}$ bewegen sich die dicken Wanderblöcke, was nicht verwunderlich ist, offenbar schneller $(2,53 \mathrm{~cm} / \mathrm{Jahr})$ als an nur $20-25^{\circ}$ geneigten Hangpartien (1,22 cm/Jahr). Alle hier genannten Daten wiesen signifikante Unterschiede auf.

Insgesamt läßt sich sagen, daß sich die Vermutungen bezüglich einer intensiven Massenverlagerung an diesem Stufenhang voll durch die Messungen bestätigen ließen. Neben dem Formenschatz der gebundenen Solifluktion, wie er auch in Abb. 6 zum Ausdruck kommt, wurde zusätzlich die Feinbeobachtung gemacht, daß sich selbst bei flacheren Neigungen von 10 bis $15^{\circ}$ am Übergang des Hanges zum schwach geneigten Hangfuß Rasendecken regelrecht in dünnen Straten von einigen Zentimetern Dicke überfließen. Dabei ist stellenweise und temporär eine starke Durchtränkung des Geländes festzustellen.

Alle oben mitgeteilten und in Tab. 1 aufgeführten Daten stammen allerdings von dem oberen Abschnitt des Stufenhanges, der nur ca. 8 - $15 \mathrm{~m}$ von der anstehenden Felswand (Meßpunkt) entfernt liegt. Am mittleren und unteren Hang wären vermutlich unter dem starken Wirken des Durchtränkungsfließens ganz ähnliche Beträge zu ermitteln, wie sie z. B. Dege (1941) mitgeteilt hat (vgl. Kap. 1).

\subsection{Sierra Nevada (Nordseite)}

Auf der N-Seite der Sierra Nevada Spaniens (BI 1:50 000: 1027 Guejar Sierra) wurden fünf Meßfelder in Höhen zwischen 2300 und $3165 \mathrm{~m}$ ü. M. angelegt. Die unteren Meßfelder 16 und 17 liegen bei 2300 und 2425 m ü. M. im Bereich des schwach aufgelösten Rasens. Die Abb. 7 (Meßfeld 16) steht stellvertretend für das Meßfeld 17 und läßt Kleinstufen und schwach entwickelte Girlanden der gehemmten Solifluktion erkennen (links unten) bzw. vermuten. Aufgrund dieses Formenschatzes der gehemmten Solifluktion an mittelsteilen Glimmerschieferhängen von 16 bis $20^{\circ}$ bei einer Vegetationsbedeckung von ca. $50 \%$ wurde von Brosche (1978 a: 74 ff., S. 110) die untere Solifluktionsgrenze bei $2300 \mathrm{~m}$ angesetzt. Der Hang ober

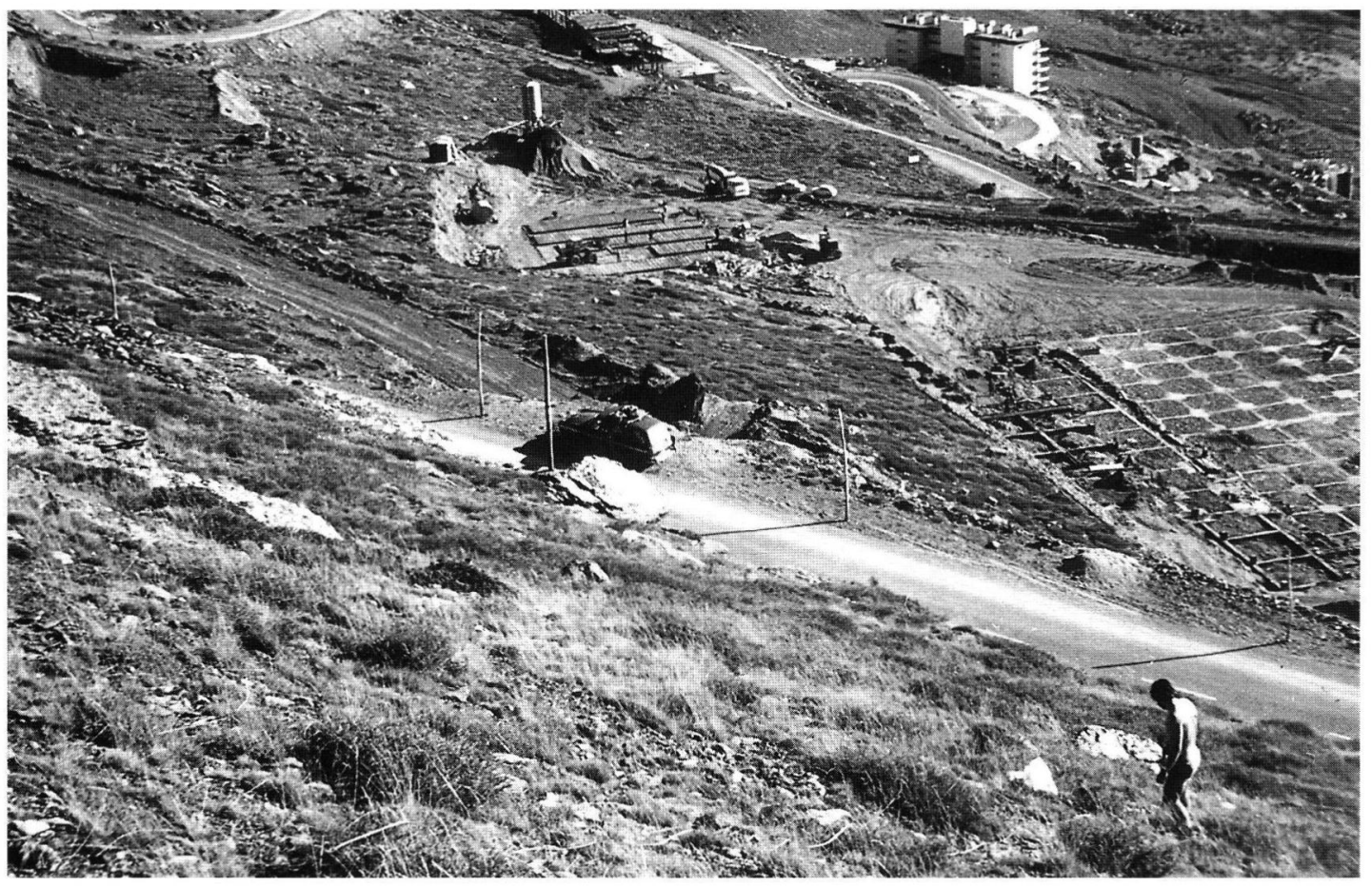

Abb. 7: Unterstes Meßfeld auf N-Seite der Sierra Nevada nördl. des Parador (Straße Granada - Veletagipfel) bei 2280 - 2300 m. Stufiger Hang mit festuca-Rasen und Zwergginster, Vegetation ca. $50 \%$. Glimmerschiefer, $16^{\circ}$, SW-Exposition; schwach entwickelte Girlanden der gehemmten Solifluktion kaum erkennbar. Meßfeld etwa parallel zum unteren Bildrand verlaufend. Im Hintergrund Skistadt der Sierra Nevada im Entstehen begriffen bei ca. $2200 \mathrm{~m}$.

Fig. 7.: Lowest experimental site on the northern side of the Sierra Nevada, north of the parador (road Granada - Veleta summit) at $2280-2300 \mathrm{~m}$. Stepped slope with festuca-turf and broom, vegetation covers $50 \%$ of the soil. Schists of glimmer, $16^{\circ}$, SW-exposition; weak developed guirlands of the "gehemmte Solifluktion" can hardly be noticed. Experimental site \pm parallel to the lower ridge of the picture. In the background "skicity" of the Sierra Nevada at $2200 \mathrm{~m}$ just being built. 
halb der Straße wird von Skifahrern nicht benutzt, dient jedoch als Weidegebiet. Wie die variierende Zahl der Messungen in Meßfeld 16 für die verschiedenen Meßzeiträume zeigt, gab es mehrfach Verluste der Holzpflöcke. Für den dreijährigen Meßzeitraum von 1972 bis 1975 konnte bei 12 ständig vermessenen Holzpflöcken ein Mittelwert von 0,17 cm/Jahr ermittelt werden. Im Zeitraum 1972 - 73 lag der Jahresdurchschnittsbetrag bei 14 Holzpflöcken aber bei 0,36 $\mathrm{cm}$. Die Minimal- und Maximalwerte zeigen keine Besonderheiten, d. h. keine bemerkenswerten "Ausreißer". Das verwundert bei $18 \mathrm{~cm}$ tief eingeschlagenen Holzpflöcken auch nicht. Das Hauptergebnis zu diesem Meßfeld lautet, daß hier bereits meßbare, wenn auch noch geringe Bodenbewegungsbeträge vorliegen, die vermutlich auch ein wenig durch Viehtritt mitverursacht werden.

Das ca. $125 \mathrm{~m}$ höher gelegene Meßfeld 17 weist bei gleicher SW-Exposition 28 - $30^{\circ}$ Neigung auf. Auch hier liegt stufiger Rasen mit festuca-Girlanden der gehemmten Solifluktion vor. Die Vermutung, daß in diesem Meßfeld, ebenfalls aus Holzpflöcken aufgebaut, höhere durchschnittliche Jahresbewegungsbeträge vorliegen würden als im Meßfeld 16, bestätigte sich für den ersten Meßzeitraum 1972/73 mit Bewe- gungsbeträgen von nur $0,13 \mathrm{~cm} / \mathrm{Jahr}$ bei 7 Messungen nicht. Bei nur 5 kontinuierlich vermessenen Holzpflöcken bestätigt sich allerdings diese Vermutung für den 3-Jahreszeitraum von 1972 bis 1975. Da die Durchschnittswerte/Jahr in beiden Meßfeldern sehr stark von einzelnen Maximalwerten beeinflußt werden können und die Zahl der Messungen in beiden Meßfeldern sehr gering ist, wird diesen Aussagen wenig Bedeutung beigemessen. Auch auf eine statistische Überprüfung dieser Werte wird verzichtet. So bleibt lediglich die Feststellung zu treffen, daß auch im Meßfeld 17 bei $2425 \mathrm{~m}$ nachweisbar mit flächenhaften Bodenbewegungen $\mathrm{zu}$ rechnen ist, die bis in $\pm 18 \mathrm{~cm}$ Tiefe hinabgehen. Dabei sind die Bodenbewegungen eigentlich nur für die Schuttfelder zwischen den Rasenstufen und -girlanden der gehemmten Solifluktion nachweisbar.

Die Meßfelder 18 - 20 liegen wenigstens $500 \mathrm{~m}$ höher als das Meßfeld 17. In diesen Höhen herrscht bereits weitflächig unbewachsener Glimmerschieferschutt vor, der zur Höhenstufe der ungebundenen Solifluktion zu zählen ist (Brosche 1978 a: 110 f.). Das rasenbewachsene muldenförmige Gelände der Abb. 8 (Meßfeld 18) stellt in dieser Höhe von $2950 \mathrm{~m}$ ü. M. eine Ausnahme dar, da hier lange Zeit im Jahr Schnee-

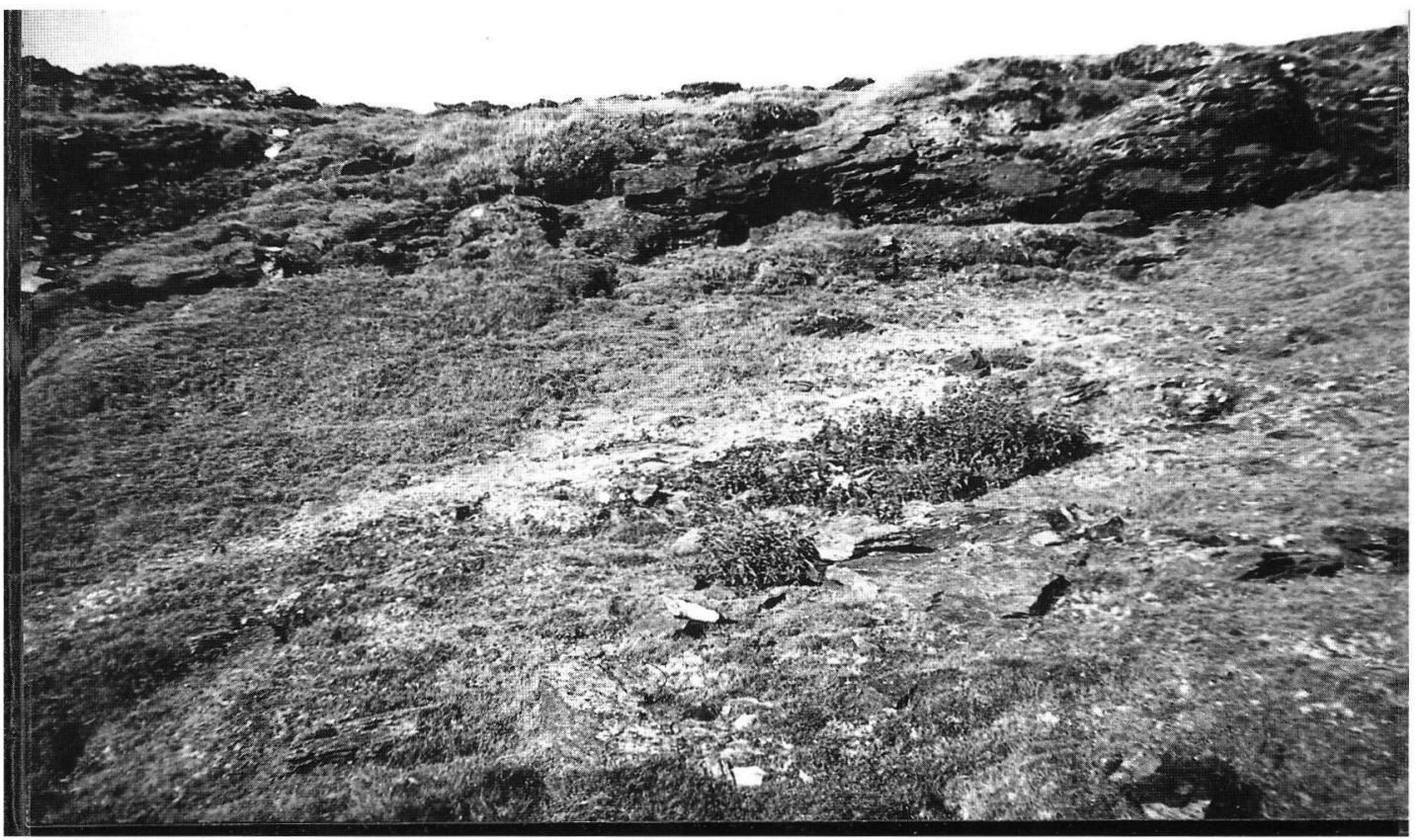

Abb. 8: Meßfeld 18 bei $2950 \mathrm{~m}$ an der Nordseite des Veletagipfels. Glimmerschiefer, 22 - 25․, S-Exposition, gebundene Solifluktion mit einigen schwach entwickelten Rasenzungen, die kuppiges Mikrorelief enthalten; feuchtes Meisfeld unterhalb eines lange anhaltenden Schneeflecks. Lokalität liegt nahe den obersten minas, westl. der Hauptstraße zum Veletagipfel nahe einem Weg, der bei 3000 m nach W zu den minas führt, wenig nördl. eines kleinen Stausees, der in Karbecken angelegt wurde.

Fig. 8: Experimental site 18 at $2950 \mathrm{~m}$ on the northern side of the Veleta summit. Schists of glimmer, 22 - 25², S-exposition, "Gebundene" solifluction with some weakly developed turf tongues, which contain "kuppiges Mikrorelief"; moist experimental site below a long lasting snow spot. Locality is situated near to the upper "minas", west of the mainroad to Veleta summit, in the neighbourhood to a dirt road, which leads to the "minas" at $3000 \mathrm{~m}$ in a westerly direction. 
deckeneinfluß besteht (vgl. auch SOUTADÉ und BAUDIÉRE 1970, deren Ergebnisse bei BROSCHE 1978 a: 75 f. ausführlich zusammengefaßt werden). Das Hauptergebnis zu den dreijährigen Messungen in diesem Meßfeld lautet: bei $22-25^{\circ}$ geneigtem zusammenhängendem Rasen mit schwach entwickelten Rasenloben herrscht in S-Exposition bereits eine deutliche $\mathrm{cm}$. Wie sich bei der Betrachtung der Meßfelder der Südseite der Sierra Nevada noch zeigen wird, sind die eben mitgeteilten jährlichen Bewegungsbeträge recht niedrig; sie würden sogar noch deutlich geringer sein, wenn nicht zwei "Ausreißer" (9,6 cm - 1973 - 1975 bzw. 10,2 cm - 1972 bis 75) auftreten würden. Der Schlüssel zur Deutung dieser geringen jährlichen Durch-

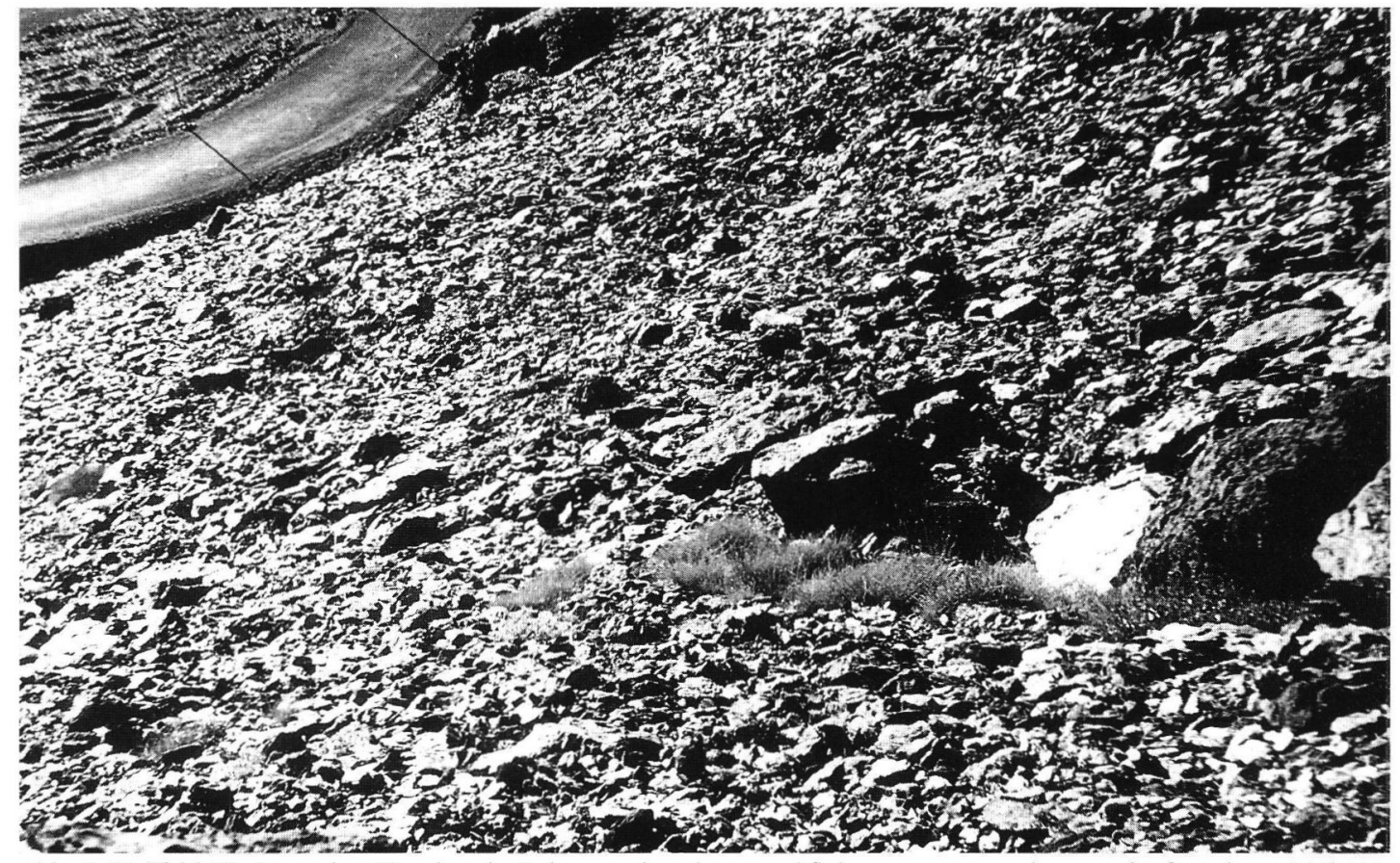

Abb. 9: Meßfeld 19. Amorpher Wanderschut der ungebundenen Solifluktion. $3000 \mathrm{~m}$, Glimmerschiefer, oberer Teil $30^{\circ}$ unterer Teil $34-35^{\circ}$. Blick schräg hangabwärts auf das Meßfeld, SSW-Exposition, kaum Feinmaterial; Meßfeld, dessen oberer Punkt bei $3000 \mathrm{~m}$ liegt, ist fast eine Schutthalde.

Fig. 9: Experimental site 19. Amorph solifluction waste of the free solifluction, $3000 \mathrm{~m}$, schists of glimmer, upper part $30^{\circ}$, lower part $34-35^{\circ}$. View oblique downwards at the experimental site, SSW-exposition, little fine material; this experimental site is nearly a "Schutthalde".

flächenhafte Bodenbewegung von $0,74 \mathrm{~cm} / \mathrm{Jahr}$ (1972/73) bzw. 0,78 cm/Jahr (1972/75). Dabei blieb die Pflockzahl von 10 konstant. Die aus der Makrobetrachtung (schwach entwickelte Loben der gebundenen Solifluktion) heraus gewonnene Vermutung zur Bodenbewegung wird durch die Messungen eindrucksvoll bestätigt und in etwa quantifiziert.

Das um 50 m höher, bei $3000 \mathrm{~m}$ liegende Meßfeld 19 (Abb. 9) liegt unterhalb großer glatter Felsflächen mit einem klar entwickelten Wassereinzugsgebiet und wird durch die ausführliche Bildcharakterisierung ausreichend vorgestellt. Es liegt bereits in der Frostschuttzone, also im Bereich der ungebundenen Solifluktion. Hier wurden 16 Steine auf einem 30 bis $35^{\circ}$ steilen Hang markiert, die von wenig oder von kei nem Feinmaterial ummantelt waren. Der durchschnittliche Bewegungsbetrag für den Zeitraum von 1972 bis 1975 betrug 0,82 cm, für den Zeitraum 1972 bis $730,49 \mathrm{~cm}$, für den Zeitraum 1973 bis 19750,98 schnittswerte liegt in der bereits erwähnten Feinmaterialarmut, d. h. in der Tatsache, daß hier bei $30-35^{\circ}$ Neigung bereits fast Schutthaldenverhältnisse vorliegen. Somit handelt es sich nicht um ein typisches Meßfeld der ungebundenen Solifluktion.

Das Meßfeld 20 dagegen liegt bei $3165 \mathrm{~m}$ direkt unterhalb einer Wand des Veletagipfels in NNW-Exposition (ein Bild liegt nicht vor.) Bei nur $19^{\circ}$ Hangneigung und reichlich Feinmaterialanteil wurden 22 (Zeitraum 1971/72), 25 (Zeitraum 1972/73) bzw. 21 Steine (Zeitraum 1971 - 1975) vermessen. Über das Meßfeld lief 1971 und 1972 noch keine Skipiste; das Veletagebiet wurde erst, wie Abb. 7 zeigt, ab 1971/72 zu einem Skipisten-Zentrum ausgebaut. Wie oben bereits angedeutet, konnten im Bereich der ungebundenen Solifluktion selbst bei nur $19^{\circ}$ Hangneigung bereits ganz deutliche jährliche durchschnittliche Bewegungsbeträge (1971 - 1972: 1,05 cm/Jahr; 1972 1973: 1,19 cm/Jahr; 1971 - 1975: 1,42 cm/Jahr) regi- 


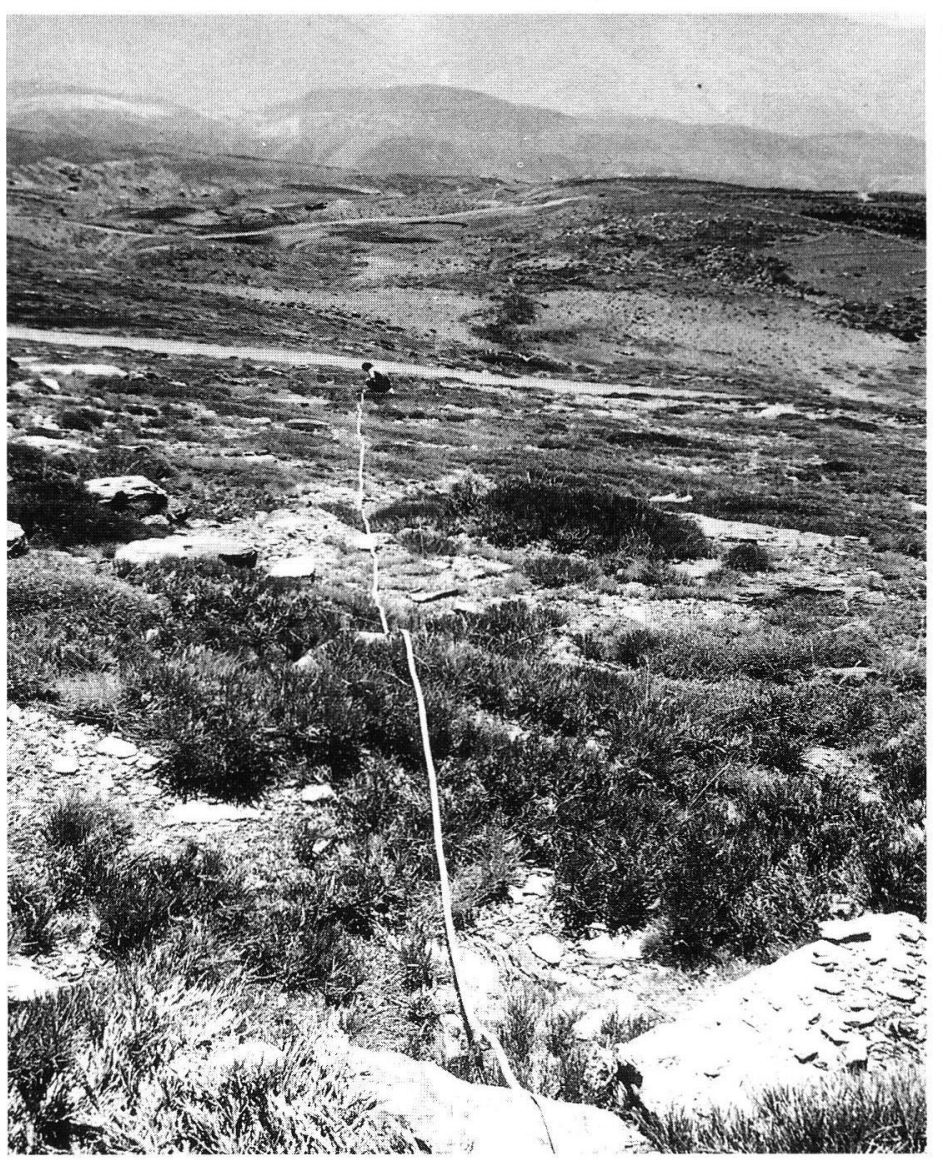

Abb. 10: Meßfeld 21 auf der Südseite der Sierra Nevada bei $1750 \mathrm{~m}$. Glimmerschiefer, $20^{\circ}$, W-Exposition. Kiefernaufforstungsgebiet mit verkrüppelten Eichenresten, Ericaarten und festuca-Rasen. Oberhalb der aufgegebenen höchsten Gehöfte gelegen. Schuttdecke $20-30 \mathrm{~cm}$ mächtig. Noch kein solifluidaler Formenschatz erkennbar. $3 \mathrm{~km}$ oberhalb $\mathrm{Ca}$ pileira an Piste Capileira - Veletagipfel.

Fig. 10: Experimental site 21 on the southern side of the Sierra Nevada at $1750 \mathrm{~m}$. Schists of glimmer, $20^{\circ}$, W-expositon. Afforested pine trees with crippled oaks, ericaceen plants and festuca turf. Situated above the highest former little farms. Waste $20-30 \mathrm{~cm}$ thick. Solifuidal forms not yet visible. $3 \mathrm{~km}$ upward of Capileira on the road Capileira-Veleta.

striert werden. Sie bleiben auch bemerkenswert, wenn man die "Ausreißer" (11,0 cm: 1972 - 1973 bzw. 19,0 cm: 1971 - 1975) berücksichtigt. Aber die Minimalwerte (1971 - 72: 0,3 cm/Jahr; 1972 - 73: 0,5 cm/Jahr und 1971 - 1975: 1,2 cm/Jahr) zeigen an, daß alle Steine in diesem Meßfeld in deutlicher Hangabbewegung sind. Die hier ermittelten jährlichen Bewegungsbeträge werden bei der Betrachtung des Abtragungsgeschehens auf der S-Seite der Sierra Nevada, wo 13 Meßfelder vermessen wurden, zum Vergleich heranzuziehen sein.

\subsection{Sierra Nevada (Südseite)}

Die Meßfelder 21 - 33 konnten von der Piste Capileira-Veleta-Gipfel aus relativ gut erreicht werden. Bei den Meßfeldern 21 - 24 handelt es sich vermutlich insofern um einzigartige Untersuchungsobjekte, als es in der Literatur etliche Vermutungen und Äußerungen zu flächenhaften Bewegungsvorgängen in der oberen montanen Stufe gibt, jedoch $\mathrm{m}$. W. bisher keinerlei Quantifizierungen oder exakte Meßergebnisse vorliegen. Die Meßsfelder 21 - 24 (siehe Abb. 10 - 12) werden hier gemeinsam betrachtet. Die Meßfelder wurden, wie Tab. 1 zeigt, zwischen $1750 \mathrm{~m}$ (oberhalb der höchsten, 1971 bereits aufgegebenen Gehöfte mit ehemaligem Getreideanbau) und $2300 \mathrm{~m}$ ü. M. angelegt. Bei gleichem Gestein (Glimmerschiefer), etwa gleicher Hangneigung $\left(18-22,5^{\circ}\right.$ ), ähnlicher Exposition (dreimal W-, einmal S-Exposition) liegt ein Kiefernaufforstungsgebiet vor, das schwach terrassiert ist (künstliche Aufforstung) und z. T. noch Eichen in Krüppelwuchsform enthält. Die Oberfläche ist durch ein Abwechseln von Schuttfeldern (z. T. von niedrigen Rasenterrassen begrenzt) und Vegetationsinseln gekennzeichnet. Lediglich bei Untersuchungsfeld 24 $(2290$ - $2300 \mathrm{~m})$ kann man bereits vom Beginn des Auftretens von Formen der gehemmten Solifluktion sprechen. Aus Beobachtungen in der weiteren Umgebung geht hervor, daßs die obere natürliche Waldgrenze mit Kiefern etwa bei $2400 \mathrm{~m}$ ü. M. liegt (BROSCHE 1978 a: 74). Bis etwa zu dieser Höhe betreibt der Mensch auch die künstliche Aufforstung - jedoch anscheinend nicht mit durchgreifendem Erfolg. Die Einzelcharakterisierung der Meßfelder sei den Beschreibungen der Abbildungen 10 - 13 entnommen. Als Hauptergebnis sei herausgestellt, daß wie bei den untersten Meßfeldern auf der Nordseite der Sierra Nevada (Meßfelder 16 und 17 oberhalb der Skistation Höhensiedlung) auf den Schuttfeldern zwischen den 


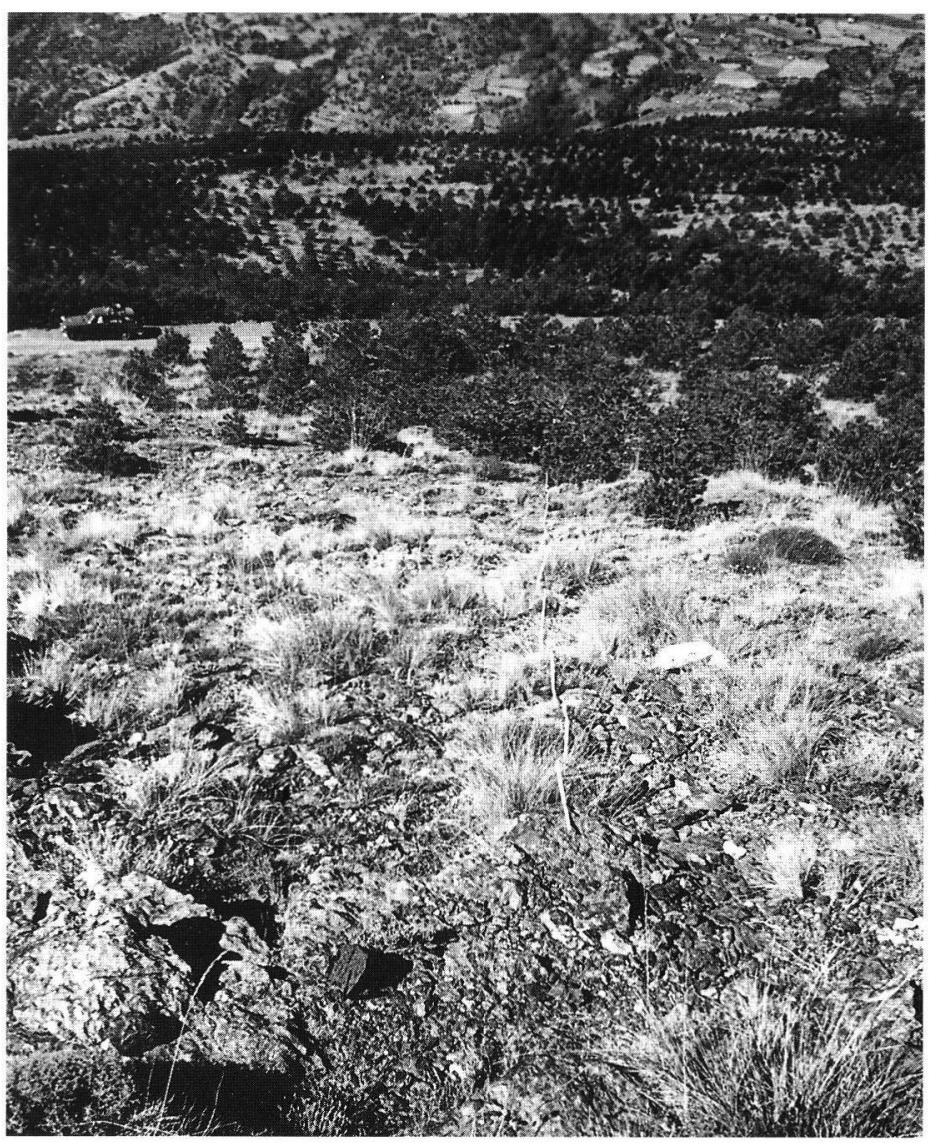

Abb. 11: Meßfeld 22 bei 1820 m, Straße Capileira - Veletagipfel (Südseite der Sierra Nevada), $150 \mathrm{~m}$ oberhalb $\mathrm{km}$-Stein 10 , $22,5^{\circ}$, W-Exposition, trockenes Meßfeld, 35 - $40 \%$ von Vegetation bedeckt, Kiefernaufforstungsgebiet, z. T. noch alte Zwergeichen.

Fig. 11: Experimental site 22 on 1820 $\mathrm{m}$, road from Capileira to Veleta (southern side of Sierra Nevada), $150 \mathrm{~m}$ above $\mathrm{km}$ rock $10,22,5^{\circ}$, W-exposition, dry experimental site, $35-40 \%$ covered by vegetation, pines afforested, interspersed with some old, crippled oaks.

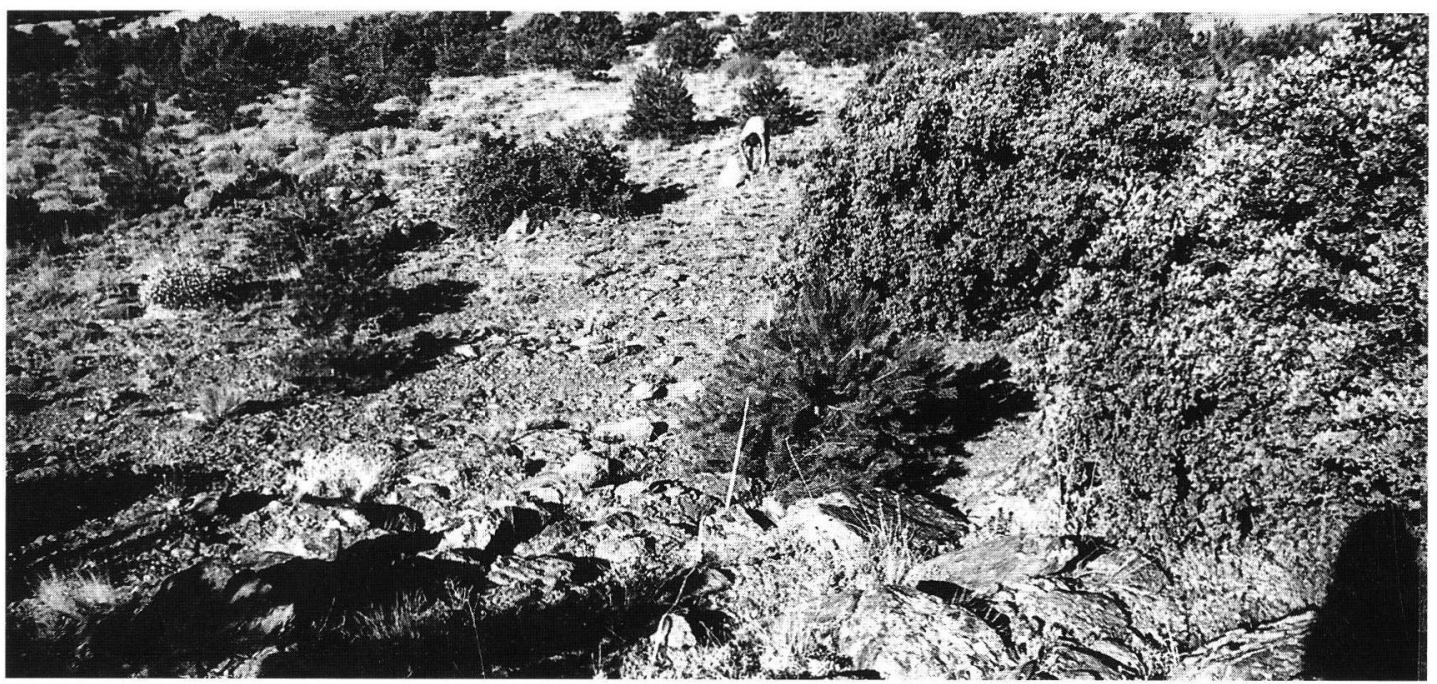

Abb. 12: Meßfeld 23 auf S-Seite der Sierra Nevada zwischen 2040 und 2050 m, 18², Glimmerschiefer, W-Exposition, Kiefernaufforstungsgebiet mit 5 - 10 Jahre alten Kiefern, künstlich terrassierter Hang. Oberhalb km-Stein 13 der Straße Capileira - Veletagipfel. Holzpflöcke auf flächenhaften Teilen der Terrassen versenkt. Schutt 20 - $30 \mathrm{~cm}$ mächtig, Pflöcke in einem Jahr um $4-6 \mathrm{~cm}$ gehoben.

Fig. 12: Experimental site 23 at the southern part of the Sierra Nevada between 2040 and 2050 m. $18^{\circ}$, schists of glimmer, W-exposition, pines planted 5 to 10 years ago, artificially terraced slope. Above km stone 13 of the road Capileira - Veleta. Wooden stakes put into soil on the plain parts of the terraces. Waste $20-30 \mathrm{~cm}$ thick, stakes elevated $4-6$ $\mathrm{cm}$ in one year. 
Vegetationsinseln entweder faktisch keine oder nur geringfügige jährliche Bewegungsbeträge (- 0,06 $\mathrm{cm} / \mathrm{Jahr}$ bis maximal $1,41 \mathrm{~cm} / \mathrm{Jahr}$ ) zu registrieren sind. Die relativ hohen Beträge dürften allerdings durch die "Ausreißer" (Maximalwerte in Tab. 1) verursacht sein. Die "Ausreißerbeträge" liegen zwar "nur" bei 8,0 bzw. $10,2 \mathrm{~cm}$. Sie dürften jedoch die relativ hohen Jahresdurchschnittswerte zu einem erheblichen Teil verursachen. Für ihr Zustandekommen dürfte am ehesten Gemsen-, Vieh- oder Hirtentritt in Frage kommen. Von einer weitflächigen Hangabwärtsverlagerung der gesamten $18-20 \mathrm{~cm}$ mächtigen Schuttschicht (incl. des vegetationsbestandenen Teils) kann man noch nicht sprechen.

Damit kann man die oberste montane Stufe wohl noch nicht - allenfalls bedingt - zur Solifluktionszone (rezente Periglazialzone) rechnen. Die Festsetzung der unteren Solifluktionsgrenze auf der S-Seite der Sierra Nevada bei 2450 - $2500 \mathrm{~m}$ ü. M. durch Brosche (1978 a: 76) scheint also, wie die Ergebnisse der Meßfelder 25 27 zeigen werden, voll berechtigt gewesen zu sein. Allgemein läßt sich feststellen, daß im untersten Meßfeld 21 bei $1750 \mathrm{~m}$ noch kaum - in keinem Zeitabschnitt - von flächenhaften Bewegungen gesprochen werden kann, in den Mesfeldern 22 - 24 jedoch zumindest in manchen Meßperioden schon deutlich meßbare Werte festgestellt werden können.

Ab $2460 \mathrm{~m}$ (Meßfeld 26) treten vermehrt Miniaturterrassetten mit festuca-Umrandung auf, die $z$. T. girlan- denförmig durchgebogen sind; von diesem Solifluktionstyp der gehemmten Solifluktion, der auf seinen Schuttfeldern Erdknospen und kurze Erdstreifen aufweist, manchmal sogar kleine Steinnetzwerke, findet man z. T. kleine zusammenhängende Vorkommen, was das Ansetzen der unteren Solifluktionsgrenze rechtfertigt. In einem abrupten Ansteigen der Bewegungsbeträge äußert sich dies allerdings nicht, wie die Betrachtung der jährlichen Durchschnittswerte der Meßffelder 25 - 27 zeigt. Diese liegen zwischen $0,09 \mathrm{~cm} / \mathrm{Jahr}$ (Meßfeld $26-1972$ bis73 und 0,71 cm (Meßfeld 25: 1972 - 1975). Die für die "Ausreißer" registrierten Maximalwerte verlieren bei diesen drei Meßfeldern deutlich an Gewicht, was ihre Einflußnahme auf den jährlichen Mittelwert betrifft. Zusammenfassend läßt sich jedoch hervorheben, daß die makroskopisch feststellbare flächenhafte Bodenverlagerung der gehemmten Solifluktion (Miniaturterrassetten und -girlanden) und die auf Schuttfeldern sichtbare frostdynamische Aktivität (Erdknospen und kurze Erdstreifen) in dieser Höhenzone (ab ca. 2450 $-2500 \mathrm{~m}$ ü. M.) sehr auffallend sind.

Im Bereich der überwiegend ungebundenen Solifluktion befindet man sich bereits bei $2720-2730 \mathrm{~m}$ im Meßfeld 28 westlich der Lokalität "El Chorillo" (dieser Name taucht u. a. an Straßenschildern an der Piste zweimal auf). Abb. 13 und die Bilderläuterung charakterisieren dieses Meßfeld auf nur $6^{\circ}$ geneigtem Gelände ausreichend. Unterhalb dieses Meßfeldes be-

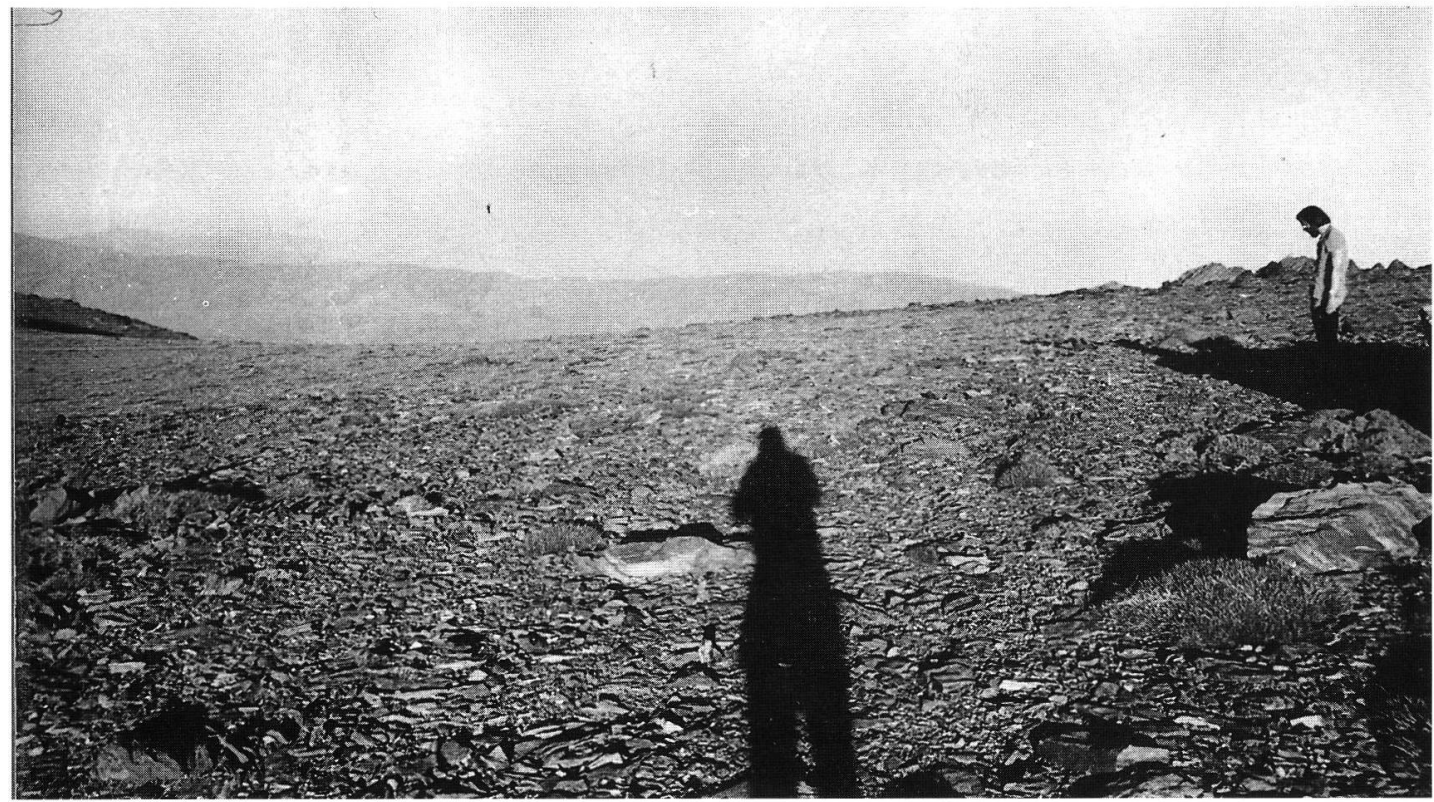

Abb. 13: Meßfeld 28, nördl. Capileira an der Straße Capileira - Veletagipfel bei 2720 - 2730 m, westl. d. nördl. Schildes mit der Aufschrift "El Chorillo" auf der Südseite der Sierra Nevada. Glimmerschiefer, 6º E-Exposition. Trockenes Meßfeld mit amorpher ungebundener Solifluktion.

Fig. 13: Experimental site 28, north of Capileira on the road Capileira - Veleta at 2720 - $2730 \mathrm{~m}$, west of the northern shield with the inscription "El Chorillo". Southern side of Sierra Nevada. Schists of glimmer, 6०, E-exposition. Dry experimental site with amorph free solifluction. 
finden sich weit ausgedehnte Miniaturstreifenfelder, wie sie sonst nirgends mehr in dieser Ausdehnung auf der Iberischen Halbinsel gefunden worden sind (BROsCHE 1978 a: Abb. 36, S. 78). Hier wurden sowohl Steine als auch Holzpflöcke vermessen. Gemessen wurde in den Jahren 1972 (Erstmessung), 1973 und 1975. Die Ergebnisse lauten: Für 26 markierte Steine wurde als Jahresdurchschnittswert dreier Jahre (1972 1975) ein Wert von $0,62 \mathrm{~cm} / J a h r$, für 9 Holzpflöcke
Jahr herausgefroren und umgekippt waren.

Das Meßffeld 29 (Abb. 14 charakterisiert es) liegt östlich des oberen Schildes "El Chorillo" auf der Piste Capileira-Veletagipfel. Die ungebundene Solifluktion wird durch eine paramoartige Vegetation (aus Zwergginster und einer festuca-Art bestehend) ein wenig gehemmt. Bisweilen treten einige Schuttstufen auf, meistens liegt amorpher Schutt vor, in dem einige Erdknospen sichtbar sind. Obwohl es Anzeichen von Spü-

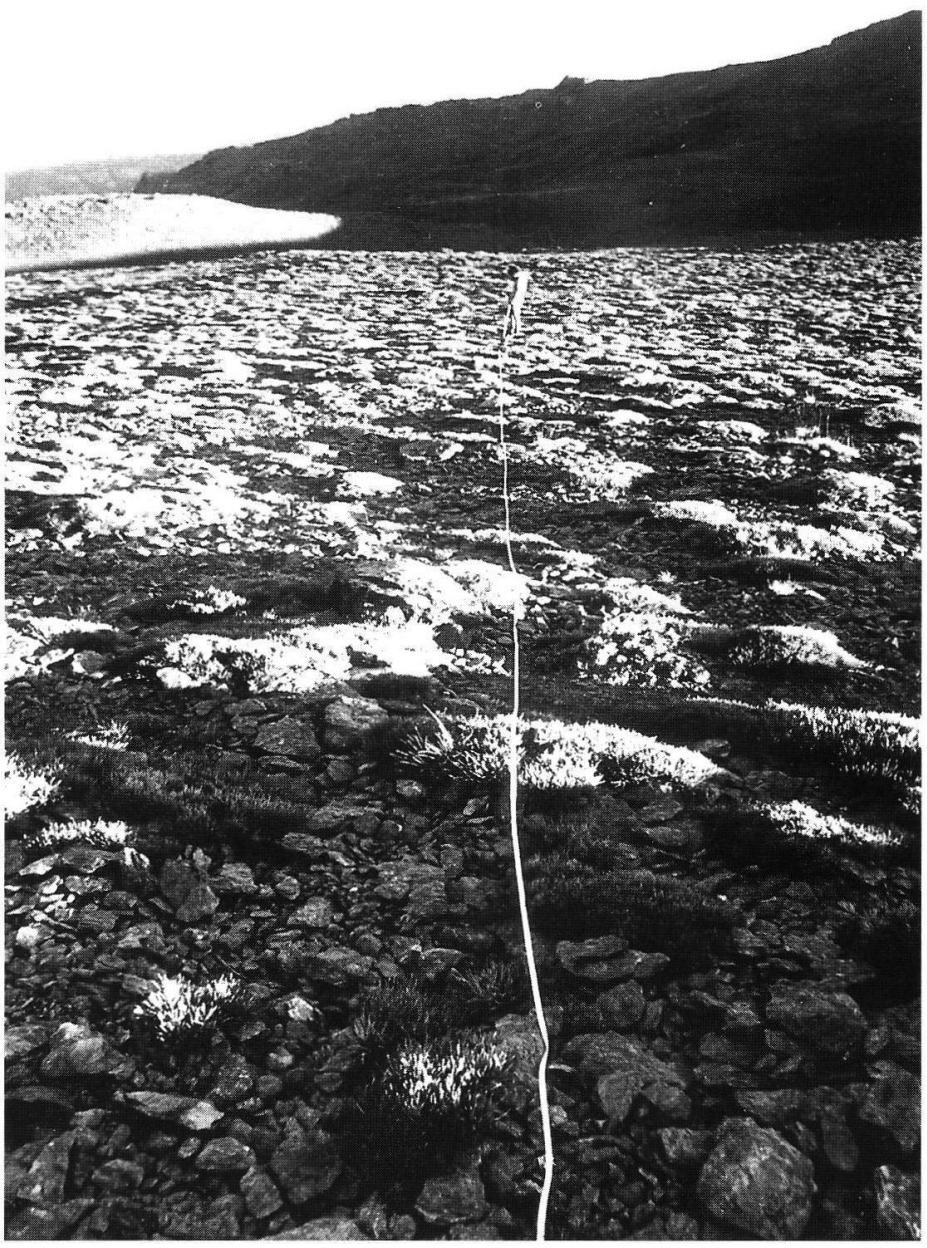

Abb. 14: Meßfeld 29. Lokalität "El Chorillo" östl. der Piste Capileira - Veletagipfel, S-Seite der Sierra Nevada, 2765 - 2775 m, $18-19^{\circ}$, Glimmerschiefer, S-Exposition. Teils ungebundene Solifluktion, teils Paramo-artige Polstervegetation. Steine und Pflöcke im trockenen Meßsfeld vermessen.

Fig. 14: Experimental site 29. Locality "El Chorillo" east of the road Capileira - Veleta, southern side of Sierra Nevada, $2765-2775$ m, $18-19^{\circ}$, schists of glimmer, south-exposition. Partly free solifluction, partly paramo-like bolster vegetation. Stones and stakes measured in the dry experimental site.

für den gleichen Zeitraum ein Jahresdurchschnittswert von $0,51 \mathrm{~cm}$ ermittelt. Die Maximalwerte (Stein: $6,8 \mathrm{~cm}$ für 3 Jahre bzw. Pflock: $2,5 \mathrm{~cm}$ für 3 Jahre) fallen kaum ins Gewicht. Die Bewegungsbeträge sind bei der doch nur geringen Hangneigung von $6^{\circ}$ als recht bedeutend anzusehen. In dieses Bild einer lebhaften frostdynamischen Aktivität passen auch die über Hunderte von Quadratmetern ausgedehnten, selbst im Hochsommer noch sehr frisch wirkenden Miniatur-Strukturböden vom Erdstreifentyp (s. o.). In diesen Erdstreifen 8 - $9 \mathrm{~cm}$ tief eingeschlagene, $10 \mathrm{~cm}$ lange runde Holzpflöcke (vgl. Kap. 2) erbrachten leider keine Meßergebnisse, da sie sämtlich nach einem lung gibt (etliche locker liegende Steine weisen darauf hin), liegt hier offenbar doch eine weitgehend undifferenzierte Wanderschuttdecke vor, in der auch einige "Bremsblöcke" i. S. Höllermanns (1964) vorkommen, die vom Schutt umflossen werden. Auch Vegetationsinseln werden vom Schutt umflossen, wie sich an der Stauchung und Kantenstellung des Schuttes erkennen läßt. Sowohl Holzpflöcke als auch markierte Steine wurden vermessen. Die Minimalwerte zeigen, daß hier die Steine und Holzpflöcke z. T. über den Zeitraum von 4 Jahren unbeweglich blieben bzw. daß vielleicht sogar Tiertritt (Gemsen) am Werk war. In der Periode 1971 - 72 wurden sowohl bei den Holz- 


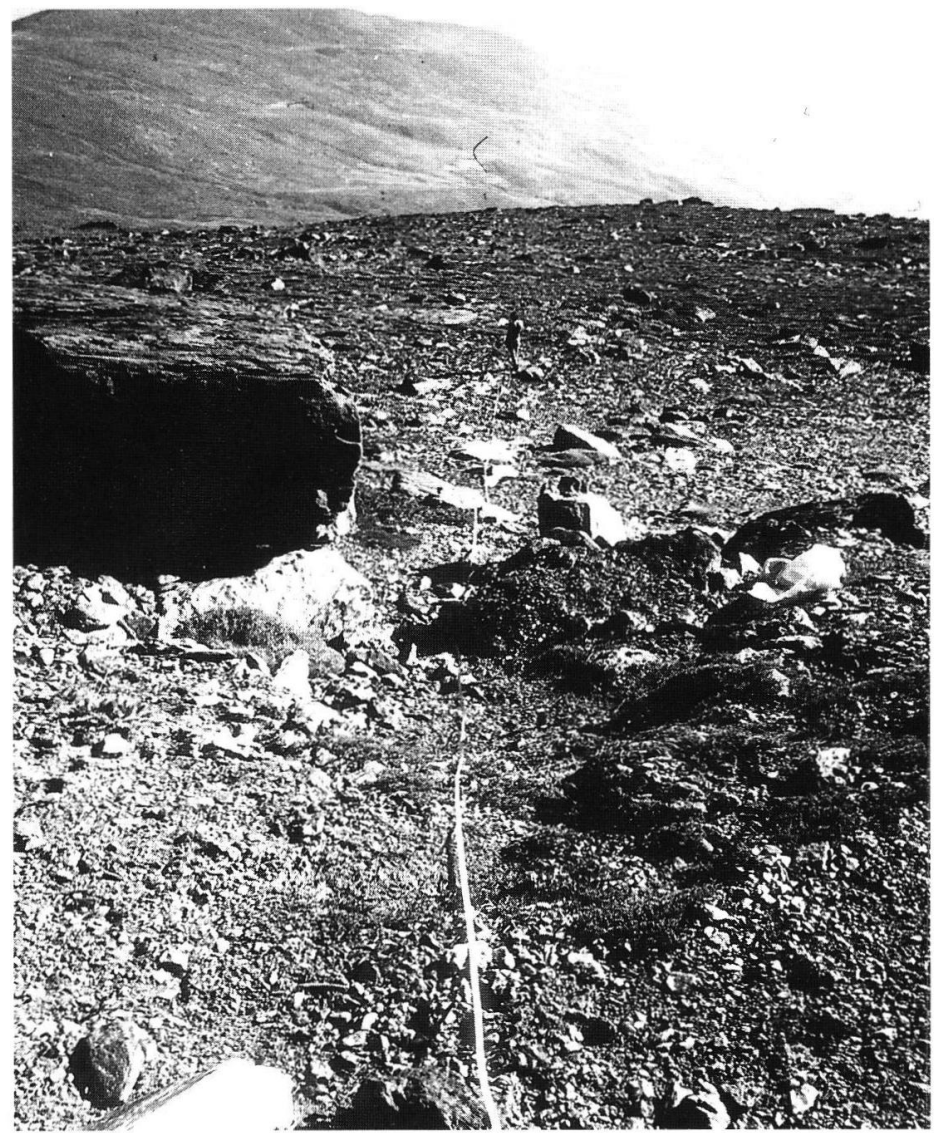

Abb. 15: Meßffeld 30. S-Seite des Mulhacén in $2950 \mathrm{~m}$ Höhe, S-Exposition, $18^{\circ} \mathrm{Nei}-$ gung, Glimmerschiefer, ungebundene Solifluktion, 220 m oberhalb Meßfeld 29; Holzpflöcke und Steine wurden vermessen. Meßfeld offenbar gut durchfeuchtet infolge langer Schneeschmelzwasserzufuhr

Fig. 15: Experimental site 30. Southern side of Mulhacén in a height of 2950 $\mathrm{m}$, S-exposition, $18^{\circ}$, schists of glimmer, free solifluction, $220 \mathrm{~m}$ above experimental site 29; stakes and stones were measured. Experimental site apparently well moistured because of long-lasting input of melting water.

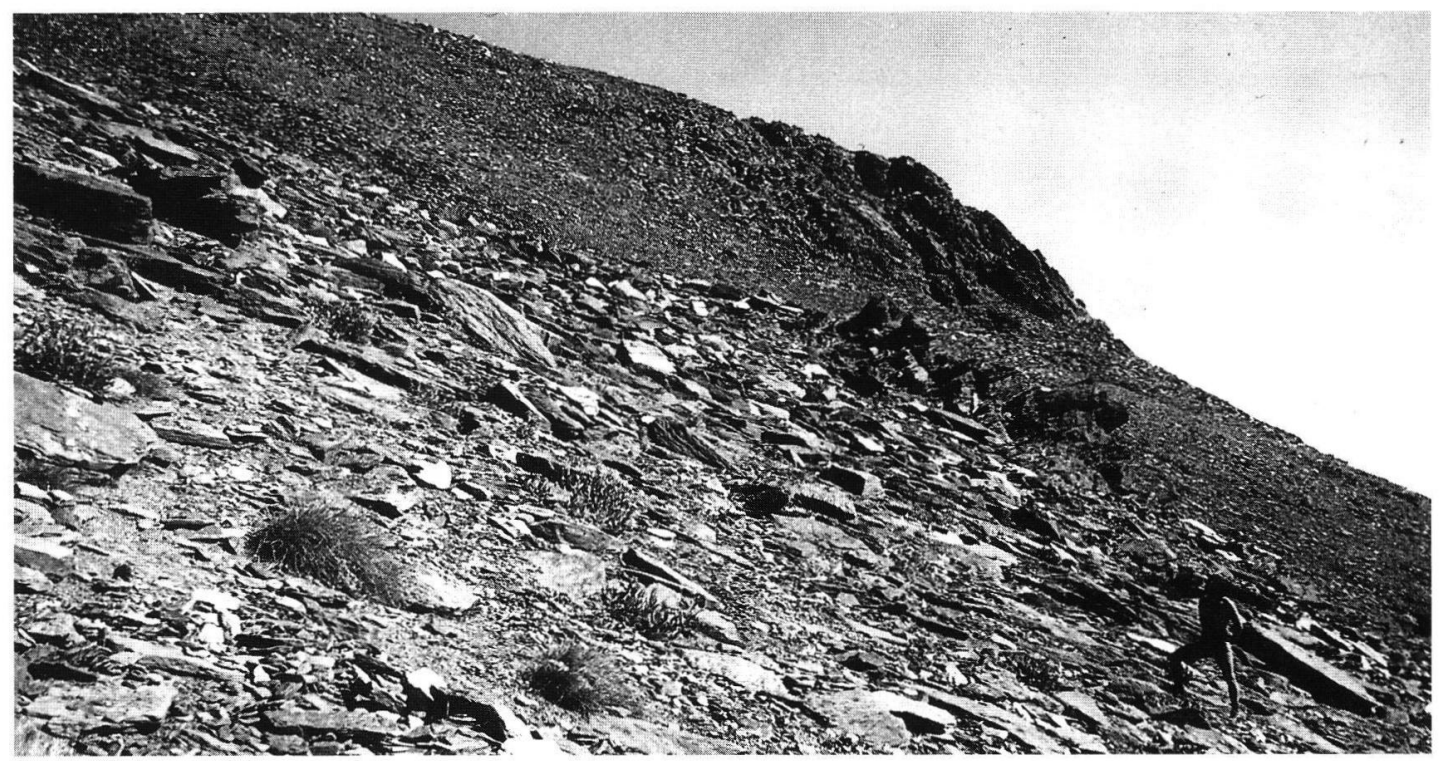

Abb. 16: Meßfeld 32 an der W-Seite des Mulhacén, 3060 m, Granatglimmerschiefer, 23 - 25․ WSW-Exposition, 50 m oberhalb km-Stein 28 der Piste Capileira - Veletagipfel, amorpher Wanderschutt der ungebundenen Solifluktion.

Fig. 16: Experimental site 32 on the W-side of Mulhacén, 3060 m, "Granatglimmerschiefer", 23 - 25, WSW-exposition, $50 \mathrm{~m}$ above $\mathrm{km}$-stone 28 of the road Capileira - Veleta. Amorph solifluction waste of free solifluction. 
pflöcken $(0,74 \mathrm{~cm} / \mathrm{Jahr})$ als auch bei den Steinen $(0,99$ $\mathrm{cm} / \mathrm{Jahr}$ ) höhere durchschnittliche Bewegungsbeträge registriert als im Jahresdurchschnitt der vierjährigen Meßperiode von 1971 bis 1975 (0,31 cm/Jahr Pflöcke, $0,34 \mathrm{~cm} / \mathrm{Jahr}$ - Steine). Die Maximalwerte sind nicht als "Ausreißer" einzustufen, d. h. sie nehmen keinen bemerkenswerten Einfluß auf die Mittelwertbildung. Bis in knapp $20 \mathrm{~cm}$ Tiefe ist hier der Boden schwach beweglich, wie sich aus den kaum differierenden Durchschnittswerten für Pflöcke und Steine ergibt. Die Messungen wurden ganz überwiegend auf den Schuttfeldern zwischen der Vegetation vorgenommen. Die recht mäßigen Bewegungsbeträge entsprechen den Erwartungen, die man an ein trockenes S-exponiertes Meßffeld mit mittlerer Hangneigung stellt.

Die Meßfelder 30 - 33 (Abb. 15 - 18) liegen allesamt im Bereich der ungebundenen Solifluktion, in der nur vereinzelt auftretende Vegetationsflecken die Schuttbewegung nicht mehr zu behindern scheinen. Das u. a. durch die Bildbeschreibung (Abb. 15) charakterisierte Meßfeld 30 ist durch eine geringe Vegetationsbedeckung und dadurch gekennzeichnet, daß hier im Höhenstockwerk der fast schon durchgängig wirkenden ungebundenen Solifluktion größere Bremsblöcke neben feinem und mittelgrobem Schutt vorkommen. Bis $3050 \mathrm{~m}$ ü. M. sind hier noch Zwergginsterflecken möglich. Im Gegensatz zum Meßsfeld 29 zeigen hier die Messungen für 1971 bis 1972 sowohl bei den Holzpflöcken als auch bei den Steinen deutlich geringere Werte $(0,34 \mathrm{~cm} / \mathrm{Jahr}$ - Pflöcke, $0,49 \mathrm{~cm} / \mathrm{Jahr}$ - Steine), als sie für die vierjährige Periode 1971 - 1975 als Jahresdurchschnittswert ermittelt werden konnten (Pflöcke: 0,67 cm/Jahr; Steine 0,76 $\mathrm{cm} / \mathrm{Jahr}$ ). Wie im Meßfeld 29 geht hier die flächenhafte Schuttverlagerung bis mindestens $20 \mathrm{~cm}$ tief hinunter, wie sich aus den kaum variierenden Werten für Pflöcke und Steine ablesen läßt. Der etwas höhere Jahresdurchschnittswert für den Zeitraum 1971 - 1975 für Steine erklärt sich möglicherweise durch den Maximalwert von $13,3 \mathrm{~cm}$ eines Steines in vier Jahren. Die gegenüber den Meßfeldern 31 - 33 (wo die Hänge $23-30,5^{\circ}$ abfallen) geringere Hangneigung ist vermutlich der Grund für die insgesamt gesehen noch recht mäßigen jährlichen Schuttbewegungsbeträge. Die drei letzten Meßfelder (31 - 33 - vgl. Abb. 16 - 18) wurden in der eindeutig zur Frostschuttzone gehörenden höchsten periglazialen Stufe der Sierra Nevada angelegt. Sie liegen alle in etwa in der gleichen Höhe zwischen $3055 \mathrm{~m}$ und $3105 \mathrm{~m}$ ü. M. Bei gleichem Ausgangsgestein (Granatglimmerschiefer) liegt zweimal (Meßfeld 31 und 32) WSW-Exposition, einmal (westl. d. Laguna de Caldera) SSE-Exposition vor.

In allen Meßfeldern wurden Steine markiert, die in der Regel im Feinmaterial "schwammen". Es ist damit zu rechnen, daß das Feinmaterial im Laufe der Jahre der Messungen in verschiedenen Fällen durch $\mathrm{Ab}$ spülung verlagert wurde und Steine ihre erdige Un-

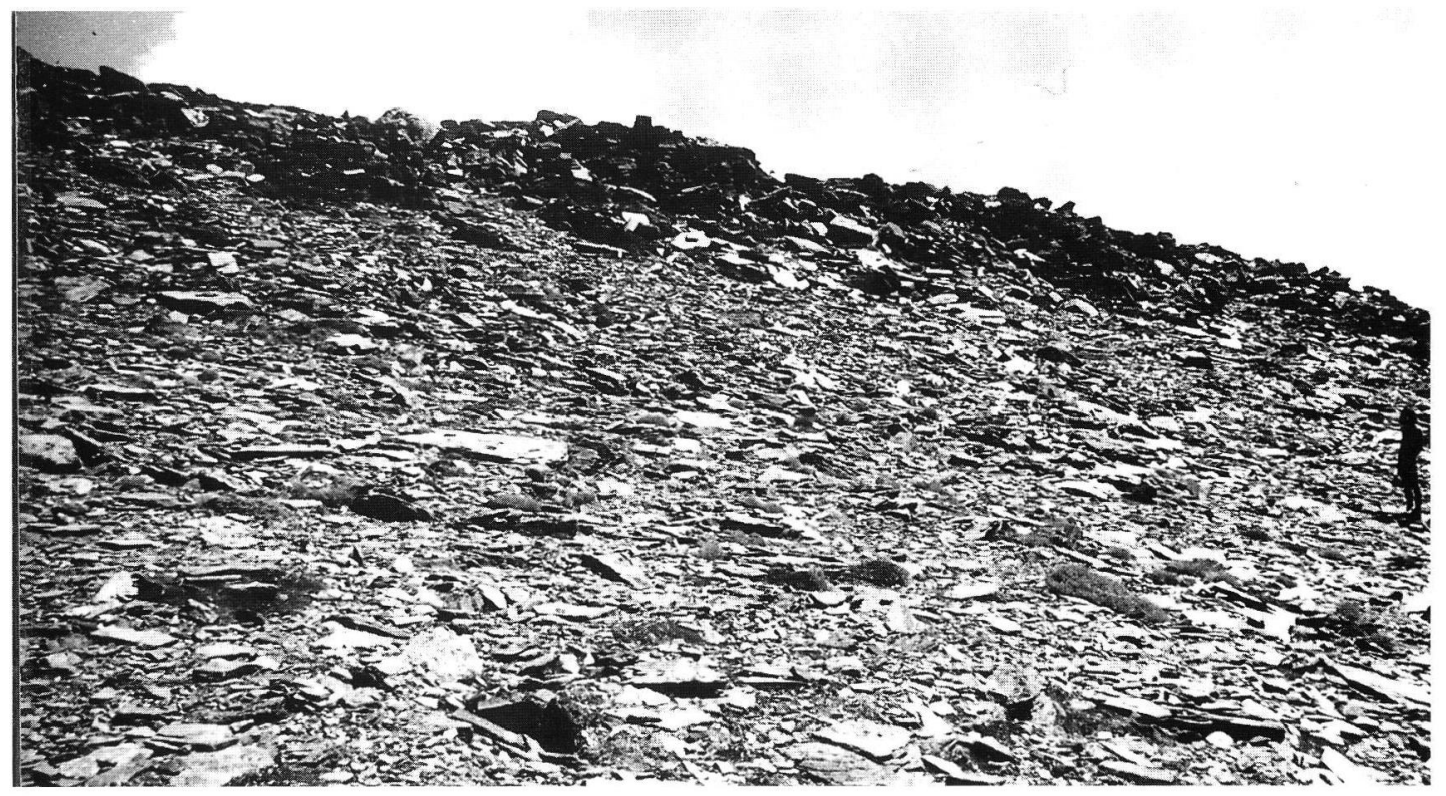

Abb. 17: Meßsfeld 31, W-Seite des Mulhacén, 3055 m, Granatglimmerschiefer, 30, $5^{\circ}$ (im oberen Bildteil unterhalb der Felsen), WSW-Exposition, $50 \mathrm{~m}$ östlich des km-Steins 28, auf Glatthang unterhalb des Mulhacén (3478 m) gelegen. Amorphe ungebundene Solifluktion.

Fig. 17: Experimental site 31, W-side of Mulhacén, $3055 \mathrm{~m}$, "Granatglimmerschiefer", 30,50 (in the upper part of the picture below the rocks), WSW-exposition, $50 \mathrm{~m}$ east of the km-stone 28, situated on a "Glatthang" below Mulhacén (3478 $\mathrm{m})$. Amorph free solifluction. 


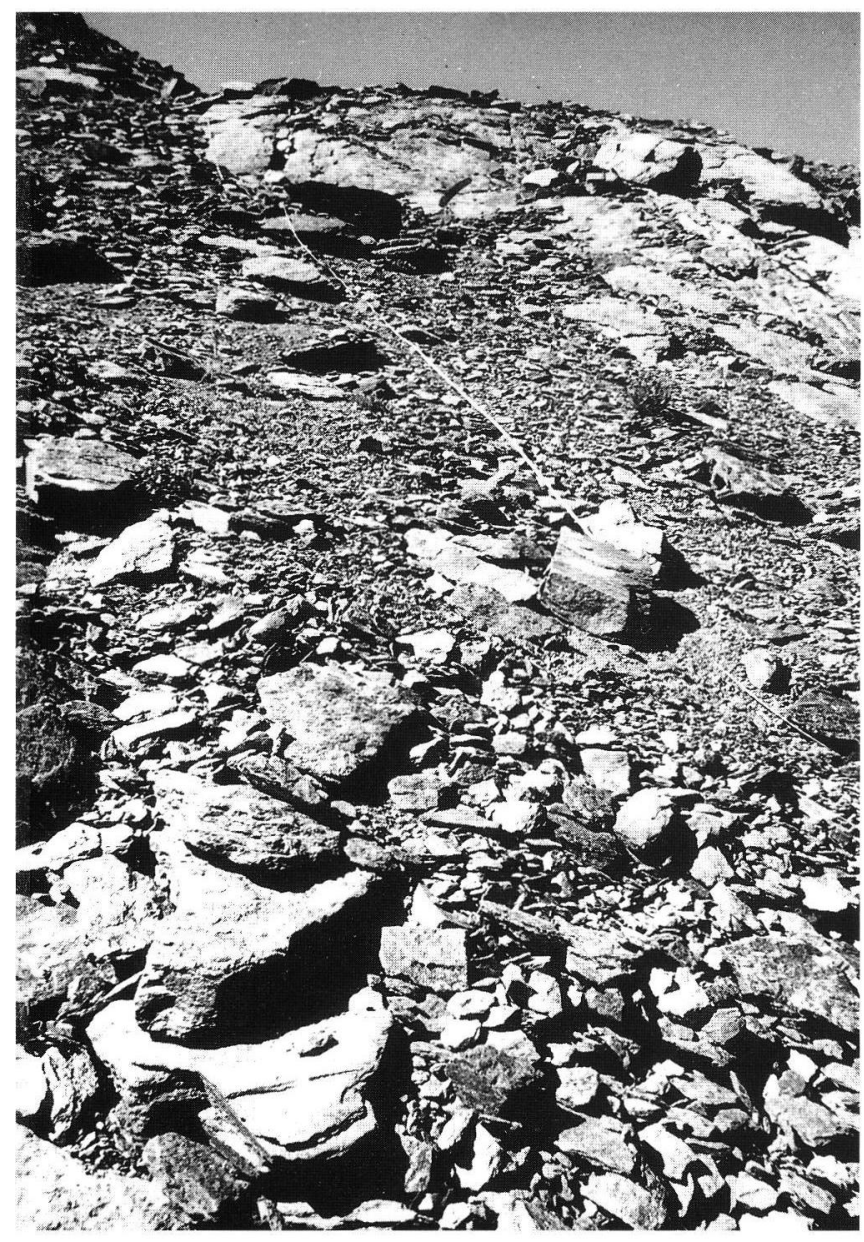

Abb. 18: Meßsfeld 33. Sierra Nevada-Südseite zwischen Mulhacén $(3478 \mathrm{~m})$ und Veleta (3392 m), westl. der Laguna de Caldera oberhalb der Piste Capileira-Veleta, 3085 - 3105 $\mathrm{m}$, Glimmerschiefer, $27^{\circ}$, SSE-Exposition, $26,1 \mathrm{~km}$ oberhalb Capileira. Ungebundene Solifluktion. Im Feinmaterial "Kräuselboden" i. S. Trolls (1944) und Kammeisenstreifenboden entwickelt, daneben Feinerdeknospen.

Fig. 18: Experimental site 33. Southern side of Sierra Nevada between Mulhacén $(3478 \mathrm{~m})$ and Veleta $(3392 \mathrm{~m})$, west of Laguna de Caldera above the road $\mathrm{Ca}$ pileira - Veleta, $3085-3105 \mathrm{~m}$, schists of glimmer, $27^{\circ}$, SSE-exposition, $26,1 \mathrm{~km}$ above Capileira. Free solifluction. In the finer material "Kräuselboden" in the sense of Troll (1944) and "Kammeisstreifenboden" with "Erdknospen".

terlage verloren haben. Die Annahme vor Anlage der Meßfelder lautete, daß hier recht deutliche Schuttdeckenbewegungsbeträge zu ermitteln seien, die denen in der Frostschuttzone der Picos de Europa (Meßfelder 5 und 6) nahekommen würden. Die ermittelten jährlichen Bewegungsbeträge:

\section{Meßfeld 31: $30,5^{\circ}$ Neigung \\ 1972 - 1975: 3,67 cm/Jahr \\ 1972 - 1973: 3,63 cm/Jahr \\ Meßfeld 32: 23 - $25^{\circ}$ Neigung \\ 1972 - 1975: 2,62 cm/Jahr \\ 1972 - 1973: 2,54 cm/Jahr \\ Meßfeld 33: $27^{\circ}$ Neigung \\ 1971 - 1975: 1,69 cm/Jahr \\ 1971 - 1972: $0,91 \mathrm{~cm} / \mathrm{Jahr}$}

bestätigen diese Annahme in eindringlicher Weise. Außerdem ist zweifelsfrei abzuleiten, daß die Hänge mit der größten Hangneigung $\left(30,5^{\circ}\right)$ bei sonst gleichen Bedingungen auch die höchsten jährlichen durchschnittlichen Bewegungsbeträge erbrachten
$(3,76 \mathrm{~cm} / \mathrm{Jahr}$ bzw. 3,63 cm/Jahr). In allen Fällen handelte es sich um amorphe Solifluktionshänge, die durch Wanderungsstaublöcke und beim Übergang vom steileren zum etwas flacheren Hang durch Schuttzungen gekennzeichnet waren. Bis in die höchsten Höhen der Meßffelder (und auch der höchsten Berge Veleta 3392 m und Mulhacén 3478 m) stellt der Granatglimmerschiefer - ähnlich wie der devonische Kalk der Picos de Europa - ein feinkörniges, lehmig-toniges Verwitterungssubstrat zur Verfügung, das auf Frostwechsel entsprechend reagiert. In allen drei Meßfeldern wurden sowohl für die drei - bzw. vierjährige Meßsperiode ähnlich hohe Maximalwerte ermittelt $(27,8 \mathrm{~cm} ; 26,3 \mathrm{~cm} ; 26,0 \mathrm{~cm})$ wie auch für eine einjährige Meßperiode $(8,8 \mathrm{~cm} ; 10,3 \mathrm{~cm} ; 10,8 \mathrm{~cm})$.

Nähme man nur einen "Tiefgang" der Schuttbewegung von 0,2 $\mathrm{m}$ an, wie er (vgl. Holzpflockmeßergebnisse der Meßfelder 29 und 30) auch für den Höhenbereich von 3050 bis $3105 \mathrm{~m}$ Höhe als Mindestwert zu erschließen ist, so könnte man den jährlichen Massentransport für 23 - 30,5 geneigte Granatglimmerschieferhänge quantitativ bilanzieren. Auf 
allen in Abb. 16 - 18 dargestellten Hängen wurde mehrfach bis aufs Anstehende, das in 0,5-0,8 m Tiefe lag, oder auf ähnliche Tiefen gegraben, ohne das Anstehende zu erreichen. Ein Permafrostboden konnte jedoch nicht festgestellt werden.

\section{Ergebnisse}

1. Der Frage, ob bereits in der montanen Zone oder in Aufforstungsgebieten nahe der natürlichen Waldgrenze meßbare solifluidiale Massenbewegungen vorliegen, wurde in den Picos de Europa, in der Peña Prieta und auf der Südseite der Sierra Nevada nachgegangen. Die Frage konnte positiv beantwortet werden. Jedoch ist die Einschränkung zu machen, daß im feuchten Norden die montane Stufe mit flächenhaft entwickeltem Rasen bestanden ist und damit der Beweidung durch Großvieh unterliegt. Der Viehtritt dürfte damit einen gewissen Einfluß auf die Hangabbewegungen haben. In der Sierra Nevada (S-Seite) dagegen liegt wegen der spärlichen Vegetation kein Großviehauftrieb vor. Hier sind frostdynamische Prozesse (Gesteinsauffrieren, Erdknospenbildung, Bildung kurzer Erdstreifen) bereits makroskopisch erkennbar. Im unteren Meßfeld bei $1750 \mathrm{~m}$ (die natürliche Waldgrenze liegt bei ca. $2400 \mathrm{~m}$ ) sind noch fast keine bzw. sehr geringe jährliche Verlagerungsbeträge erkennbar ( 0,02 bzw. $0,23 \mathrm{~cm} / \mathrm{Jahr})$. Im oberen Teil der montanen Stufe, einem Kiefernaufforstungsgebiet, sind die Hangabwärtsbewegungen schon deutlicher (Meßfelder 22 bis 24: 0,67 bis maximal $1,41 \mathrm{~cm}$, aber auch keine Bewegung kommt vor - Meßfeld 24, Zeitraum 1973 - 75).

2. Die höchsten Bewegungsbeträge wurden im gut wasserdurchtränkten Rasengelände der Sierra de Urbión mit Werten von $6,5 \mathrm{~cm} / \mathrm{Jahr}$ ermittelt. Allerdings dürfte hier ein Durchtränkungsfließen i. S. SøRENSENs (1935) nach der Schneeschmelze einen großen Einfluß ausüben. In den Picos de Europa wurden im Höhenstockwerk der ungebundenen Solifluktion bei 25 - $28^{\circ}$ geneigten amorphen Solifluktionshängen bei S-Exposition maximale jährliche Bewegungsbeträge von $1,66 \mathrm{~cm} / \mathrm{J}$ ahr bzw. $1,8 \mathrm{~cm} / \mathrm{Jahr}$ ermittelt. Hier liegt noch kein Dauerfrostboden vor. Auf vergleichbaren Solifluktionshängen in der Sierra Nevada Südspaniens liegen die Werte deutlich höher (die fünf höchsten jährlichen Bewegungsbeträge lauten 1,69 cm/Jahr; $2,54 \mathrm{~cm} / \mathrm{Jahr} ; 2,62 \mathrm{~cm} / \mathrm{Jahr} ; 3,63 \mathrm{~cm} / \mathrm{Jahr} ; 3,76$ $\mathrm{cm} / \mathrm{Jahr}$ ). Hier lag WSW- bzW. SSE-Exposition vor.

3. Aus dem Rahmen fallende geringere jährliche Bewegungsbeträge im Höhenstockwerk der ungebundenen Solifluktion ließen sich in Einzelfällen durch eine längere Schneedeckendauer erklären, womit die Ergebnisse GAMPERs $(1983,1985)$ erhärtet werden.

4. Es scheint mir erwiesen zu sein, daß im Höhenstockwerk der ungebundenen Solifluktion eine größere Hangneigung auch höhere Bewegungsbeträge her- vorruft (vgl. die Meßfelder 31 und 32 - Abb. 16 und 17).

5. Mit zunehmender Höhe und abnehmender Vegetation nimmt die Intensität der solifludialen Massenverlagerungen eindeutig $\mathrm{zu}$. Lediglich durch Schmelzwässer gut versorgte geschlossene Rasenflächen über einem tonigen Verwitterungssubstrat (Sierra de Urbión) bewegen sich durch Durchtränkungsfließen (s. o.) schneller als amorphe Wanderschuttdecken im Höhenstockwerk der ungebundenen Solifluktion.

6. Neben den flächenhaften solifluidalen Bodenverlagerungsprozessen führen weitere Prozesse zur Verlagerung von Feinmaterial oder Steinen. Viehtritt, Durchtränkungsfließen (s. o.), Abspülung von Feinmaterial, Unterspülung von Steinen und daraus resultierendes Rutschen. Vermutlich spielt auch Schneedruck und Abgleiten von Schnee (beides konnte auf den Meßfeldern nicht nachgewiesen werden) zum Herabgleiten von Schutt eine Rolle. Auch Schuttrutschen auf Schneefeldern ist zu berücksichtigen, konnte jedoch bei den vermessenen Steinen und Pflöcken nicht nachgewiesen werden. Im Rahmen der Beobachtung des Durchtränkungsfließens in der Sierra de Urbión wurde bewiesen, wie mehrere Rasenhorizonte übereinander geflossen waren, die durch dünne Tonschichten voneinander getrennt waren, ohne daß die klassischen Rasenüberwälzungen der Stirn von Loben entstanden wären.

7. Die Bewegungsbeträge waren in jedem Jahr nicht immer gleich oder annähernd gleich. Das kann seinen Grund darin haben, daß die Messungen zu verschiedenen Zeiten des Sommers vorgenommen worden sind, als das Abtauen der Schneedecke unterschiedlich weit vorangeschritten war. Der Vorgang der "gelifluction" i. S. Washburns (1969) bzw. das "viscous flowing" i. S. JAHNs (1961) konnte also bei manchen Messungen noch nicht ins Gewicht fallen. Eng mit einer lange anhaltenden Schneedeckendauer hängen das von oben eindringende Tauen des Bodens und seine Beweglichkeit zusammen.

8. Zur Rolle der Vegetation läßt sich sagen, daß bei normalen "trockenen" Meßfeldern eine geschlossene Vegetationsdecke offenbar hemmend auf die solifluidalen Massenverlagerungen wirkt. Die höchsten Bewegungsbeträge auf trockenen S-, SW- und SSWexponierten Hängen wurden, wie schon erwähnt, im Bereich der ungebundenen Solifluktion (Sierra Nevada) registriert (s. o.). Andererseits hindert eine geschlossene Rasendecke bei sehr feuchten Meßfeldern in NE-Exposition nicht das Herabgleiten geschlossener dünner Rasendecken (Durchtränkungsfließßen), zumal bei tonigem Ausgangssubstrat (s. o.).

9. In einem Meßsfeld (Meßsfeld 6 in den Picos de Europa) bewegten sich die oberflächlich im Feinmaterial "schwimmenden" Steine in signifikant schnellerer Weise $(0,62 \mathrm{~cm} / \mathrm{Jahr})$ als die knapp $20 \mathrm{~cm}$ einge- 


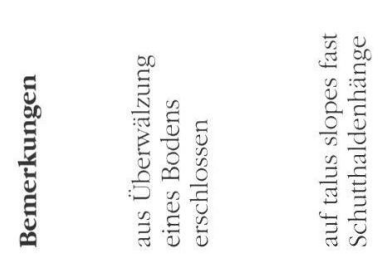

$\dot{\Xi}$
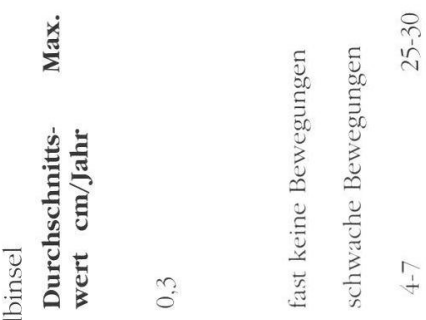

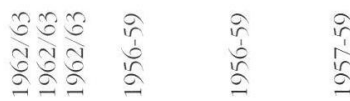

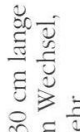

r.

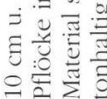

$\stackrel{0}{-}$

$\stackrel{\circ}{\text { i }}$

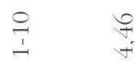

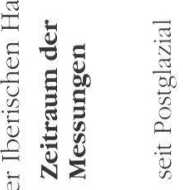

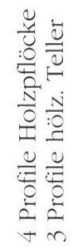

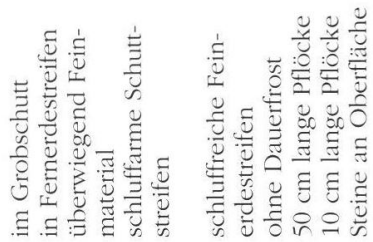

oning in

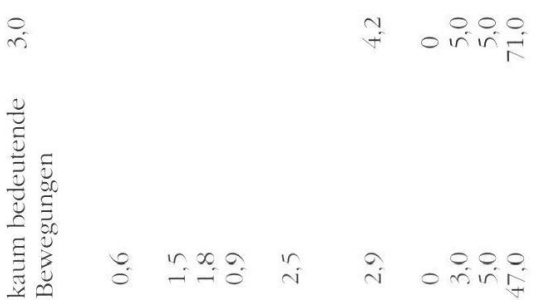

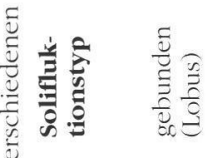

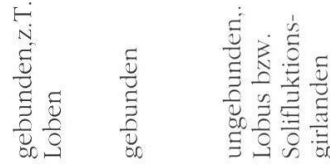

$\begin{array}{ll}\hat{n} & \hat{n} \\ i n & n \\ i n & n\end{array}$

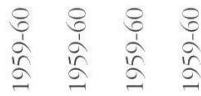

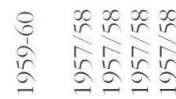

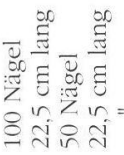

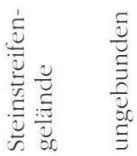

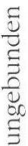

$\cong \frac{1}{\mathrm{e}}$

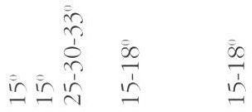

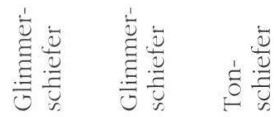

它.

m

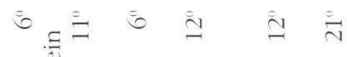

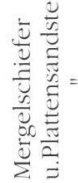

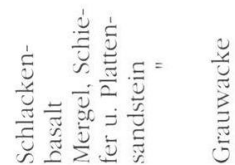

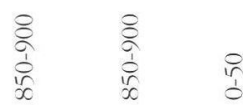

in

$\underset{\substack{1 \\ \infty \\ \infty \\ \infty}}{8}$

$\stackrel{ }{ }$

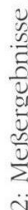

곤.

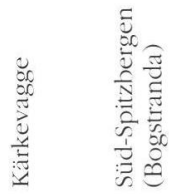

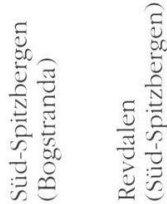

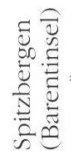

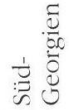

莺冚

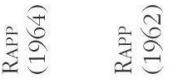

농

ํㅏㅇ

色五 


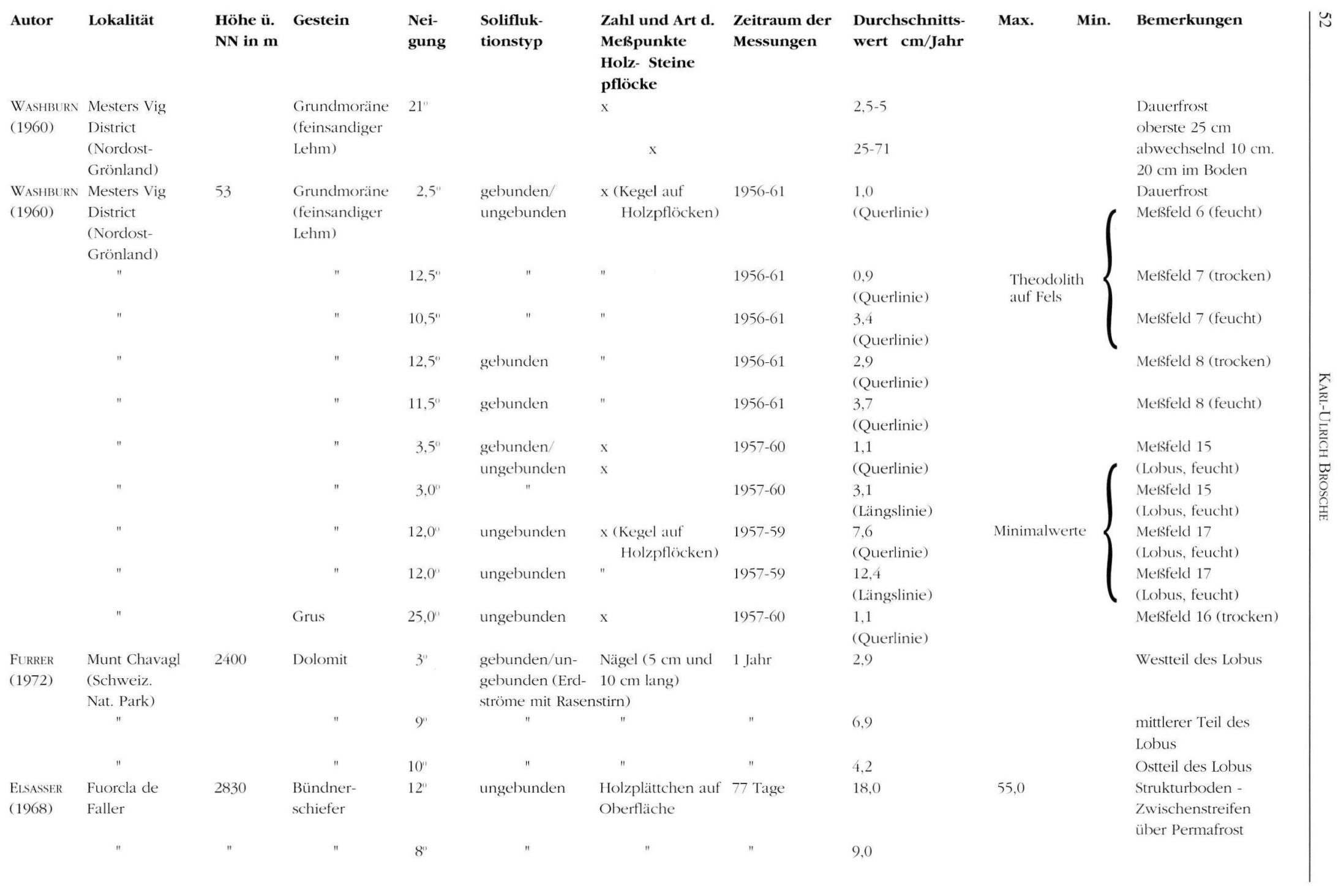




\section{Autor Lokalität}

\section{Höhe ü. Gestein
NN in $\mathbf{m}$}

Nei-

gung

Solifluk-

tionstyp

24

(nach

Cordillera Real

5000

Furrer Cerro Thacaltaya

(1972)

$\begin{array}{ll}" & 4900 \\ " & 4800 \\ " & 5000 \\ & 4800\end{array}$

Rudberg Südl. Schwed.

(1964) Lappland

(Nora Störfjell)

Nora Störfjell

\begin{tabular}{lr}
\hline$"$ & 1320 \\
$"$ & 1285 \\
$"$ & 1260 \\
$"$ & 1300 \\
& 805
\end{tabular}

805

805

930

905

900

895

gehemmt-

Glimmer-

schiefer u.

Gneis

$\begin{array}{lr}" & 9^{\prime \prime} \\ " & 10^{\prime \prime} \\ " & 14^{\circ} \\ " & 25^{\circ} \\ " & 5^{\circ}\end{array}$

"
Zahl und Art d. Zeitraum der Durchschnitts-

Meßpunkte Messungen wert $\mathrm{cm} / \mathrm{J}$ ahr

Holz- Steine

pflöcke

ungebunden

34 Tage

$20-45$

20-28

$60-70$

$5 \mathrm{~cm}$ lange

Nägel
15

$9^{n}$
$10^{n}$

$14^{\circ}$
$25^{\circ}$

"

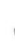

$15^{\circ}$

$10^{\circ}$

" gebunden ungebunden

\footnotetext{
$x+(58)$
}

$"$
$"$
$"$

$x(18)$

$\mathrm{x}(53)$

$\mathrm{x}(62)$
$\mathrm{x}(74)$

$x(52)$

$\times(22)$

$\mathrm{x}(17)$

$\mathrm{x}(24)$

x (48)

$x(63)$
$\times(38)$

x (38)

$1957-6$.
$1957-6$

1957-63

$1957-63$
$1957-63$

$1055-63$

1955-63

1955-56

1956-57

1955-62

1957-63

0,8

1957-63
$\operatorname{Max}$

Min. Bemerkungen

Steinzungen

Steinzungen

(Zentraler Bereich)

Bewegung erst nach Herausfrieren der

Nägel (nur Kammeissolifluktion)

nur Oberflächen-

bewegung gemessen

in Steinstreifen

0,5
0,5
0,7
1,1
2,8

0,0

"

feuchter Rasenhang, Werte sind Minimumwerte

Lobus am Fuß eines

hohen Hanges

dünne Solifluktions-

decke, teils schwache Loben, teils Mikro-

solifluktion

Mikrosolifluktion der- 
schlagenen Holzpflöcke (Kalk Picos de Europa). Eventuell taut hier infolge einer recht langen Schneedeckendauer, die zuweilen das Nachmessen des unteren Meßfeldteiles unmöglich machte, der Boden recht spät erst bis in $20 \mathrm{~cm}$ Tiefe auf, so daß die obersten Bodenschichten bis ca. $10 \mathrm{~cm}$ Tiefe beweglicher sind. Dieses Ergebnis kann jedoch nicht verallgemeinert werden, wie die Ergebnisse der Meßfelder 29 und 30 (Südseite der Sierra Nevada) zeigen. Hier ergaben sich keine signifikanten Unterschiede der Bewegungsgeschwindigkeit der Steine und Pflöcke.

\section{Danksagung}

Bei der Installation, Erstvermessung und mehrfachen Nachmessung von mehr als 34 Meßfeldern waren mir behilflich: Herr Studienrat G. Baldschun, Berlin, Herr Realschullehrer G. Schlichtholz †, Berlin, Herr Priv.Doz. Dr. M. Walther, Berlin, meine Ehefrau und meine Eltern. Allen gilt mein besonderer Dank.

Dem Fachbereich Geowissenschaften der FU Berlin danke ich für mehrere Reisezuschüsse zur Durchführung geomorphologischer, bodengeographischer und küstenmorphologischer Untersuchungen auf der Iberischen Halbinsel, in deren Verlauf auch die Messungen zum vorliegenden Beitrag gemacht werden konnten.

\section{Schriftenverzeichnis}

Alexander, C. S. \& Price, L. W. (1980): Radiocarbon dating of the rate of movement of two solifluction lobes in the Ruby Range, Yukon Territory. - Quaternary Research, V. 13: 365 - 379; Seattle.

Benedict, J. B. (1966): Radiocarbon dates from a stone banked terrace in the Colorado Rocky Mountains, USA. Geografiska Annaler, V. 48 A: 24 - 31.

- (1976): Frost creep and gelifluction features: A review. -Quaternary Research. v. 6: 55-76; Seattle.

Brosche, K.-U. (1971 a): Beobachtungen an rezenten Periglazialerscheinungen in einigen Hochgebirgen der Iberischen Halbinsel (Sierra Segura, Sierra de Gredos, Serra da Estrêla, Sierra del Moncayo). - Die Erde 102: 34-52; Berlin.

- (1971 b): Neue Beobachtungen zu vorzeitlichen Periglazialerscheinungen im Ebrobecken. - Zeitschrift $\mathrm{f}$. Geomorphologie. N. F. 15: 107 - 114; Berlin.

- (1972): Vorzeitliche Periglazialerscheinungen im Ebrobecken in der Umgebung von Zaragoza sowie ein Beitrag zur Ausdehnung von Schutt- und Blockdecken im Zentral- und Westteil der Iberischen Halbinsel. - HansPoser-Festschrift. Göttinger Geogr. Abh. 60 : 34-52; Göttingen.

- (1974): Ergebnisse von Messungen von Abtragungsvorgängen in rezenten Periglazialgebieten. Manuskript Habil.-Vortrag vom 23.10.1974.

- (1978 a): Beiträge zum rezenten und vorzeitlichen periglazialen Formenschatz auf der Iberischen Halbinsel. - Abhandlungen des Geographischen Instituts, Sonderhefte, Bd. 1: 287 S.; Berlin.
- (1978 b): Ergebnisse einer vergleichenden Studie zum rezenten und vorzeitlichen periglazialen Formenschatz auf der Iberischen Halbinsel. - Biuletyn Peryglacjalny, 27: 53-103, 16 Abb., 4 Fig., 2 Tab.; Lódź.

- (1983): Das Glatthangrelief auf der Iberischen Halbinsel - Verbreitung, Aufbau und Genese. - Mesoformen des Reliefs im heutigen Periglazialraum. Bericht über ein Symposium. Abhandlungen der Akademie der Wissenschaften in Göttingen, Mathematisch-Physikalische Klasse - Herausgegeben von Hans Poser und Ekkehard Schunke, 3. Folge Nr. 35: 214-240; Göttingen.

- (1986): Pleistozäne Periglazialstrukturen in den Ebroterrassen bei Zaragoza. Biuletyn Peryglacjalny, 30: 4556; Lódź.

BüDEL, J. (1948): Die klimamorphologischen Zonen der Polarländer. - Erdkunde 2: 22-53; Bonn.

- (1953): Die "periglazial"-morphologischen Wirkungen des Eiszeitklimas auf der ganzen Erde. - Erdkunde 7: 249-266; Bonn.

- (1960): Die Frostschuttzone Südostspitzbergens. - Colloquium Geograficum 6: 105 S.; Bonn.

- (1961): Die Abtragungsvorgänge auf Spitzbergen im Umkreis der Barentsinsel. - Deutscher Geographentag Köln, Tagungsberichte und Wissenschaftliche Abhandlungen: 337 - 375; Wiesbaden.

DEGE, W. (1941): Landformende Vorgänge im eisnahen Gebiet Spitzbergens. - Petermanns Geogr. Mitteilungen, 87: 81-97 und 113-122; Gotha.

DYLIK, J. (1953): Periglacial investigations in Poland. - Bull. Soc. Sci. Lettr. IV. 2. Lódź.

ELSASSER, H. (1968): Untersuchungen an Strukturböden im Kanton Graubünden. - Dissertation Phil. Fak. II der Universität Zürich. Zürich.

FITZE, P. (1971): Messungen von Bodenbewegungen auf West-Spitzbergen. - Geographica Helvetica, 26: 148-152; Bern.

FrenCH, H. M. (1974): Mass wasting at Sachs Harbour, Banks Island, NWT, Canada. - Arctic and Alpine Research, 6: 71-78; Boulder.

- (1976): The Periglacial Environment. - 309 S.; Longman London and New York.

Furrer, G. (1972): Bewegungsmessungen auf Solifluktionsdecken. - Zeitschr. f. Geomorphologie, N.F., Suppl. Bd. 13: 87-101; Berlin, Stuttgart.

- (1977): Klimaschwankungen im Postglazial im Spiegel fossiler Böden: Ein Versuch im Schweizerischen Nationalpark. In: FreNzel, B. (ed.) Dendrochronologie und postglaziale Klimaschwankungen in Europa. Erdwissenschaftliche Forschung, v. 13: 267-270.

- Bachmann, F. \& Fitze, P. (1971): Erdströme als Formelemente von Solifluktionsdecken im Raum Munt Chavagl/Munt Buffalova (Schweizerischer Nationalpark): Ergebnisse der Wissenschaftlichen Untersuchungen im Schweizerischen Nationalpark. V. 11: 189 - 269; Bern. - Lenzinger, H. \& AMmanN, K. (1975): Klimaschwankungen während des alpinen Postglazials im Spiegel fossiler Böden. Vierteljahresschrift d. Naturforschenden Gesellschaft in Zürich. V. 120, 15-31; Zürich.

GAMPER, M. (1981): Heutige Solifluktionsbeträge von Erdströmen und klimamorphologische Interpretation fossiler Böden: Ergebnisse der Wissenschaftlichen Untersuchungen im Schweizerischen Nationalpark. V. 15, 355-443; Bern. 
- (1982): Postglaziale Solifluktionsphasen am Albulapaß (östliche Schweizer Alpen): Physische Geographie. V. 1, 171-186, Georgr. Inst. Univ. Zürich.

- (1983): Controls and rates of movement of solifluction lobes in the Eastern Swiss Alps. In: Permafrost: Fourth International Conference, Proceedings, 328 - 333; Washington D.C.

- (1985): Morphochronologische Untersuchungen an Solifluktionszungen, Moränen und Schwemmkegeln in den Schweizer Alpen. - Eine Gliederung mit Hilfe der ${ }^{14} \mathrm{C}$-Altersbestimmung fossiler Böden. - Physische Geographie. Geographisches Institut der Universität Zürich, 17; Zürich.

GAMPER, M. \& Suter, J. (1982): Postglaziale Klimageschichte der Schweizer Alpen. Geografica Helvetica, 37: 105114; Bern.

HARrIS, C. (1973): Some factors effecting the rates and processes of periglacial mass movements. - Geografiska Annaler, 55 A: 24-28; Stockholm.

- (1981): Periglacial mass-wasting. A review of research. British Geomorphological Research Group. Research Monograph Series, $\mathbf{4}$;

Högвom, B. (1914): Über die geologische Becleutung des Frostes. - Bull. Geol. Inst. Univ. Uppsala, 11: 242-251.

Höllermayn, P. (1964): Rezente Verwitterung, Abtragung und Formenschatz in den Zentralalpen am Beispiel des oberen Suldentales (Ortlergruppe). - Zeitschr. f. Geomorph. Neue Folge, Supplementband 4: 253 S.; Berlin, Stuttgart.

JAHN, A. (1951): Zjawiska krioturbacyjne wspolczesnej i plejstocenskiej strefy peryglcjalnej (summary: Cryoturbate phenomena of the contemporary and of the Pleistocene periglacial zone). Acta Geol. Polonica, 2.

- (1960): Some remarks on evolution of slopes on Spitzbergen. - Zeitschr. f. Geomorph., Suppl. Bd. 1: 49-58; Berlin, Stuttgart.

- (1961): Quantitative analysis of some periglacial processes in Spitzbergen. - Universytet Wroclawski im Boleslawa Bieruta, zeszyty naukowe, nauki przyrodnicze, ser. B 5 (Nauka o Ziemi II): 1 - 34; Warschau.

JAECKLI, H. (1957): Gegenwartsgeologie des bündnerischen Rheingebietes. Beiträge zur Geologie der Schweiz. Geotechnische Serie, Lieferung 36: 136 S.

Michaud, J. (1950): Emploi des marques dans l'étude des movements du sol. - Revue de Géomorphologie dynamique, 1: 180-189.

- \& Cailleux, A. (1950): Vitesse du mouvement du sol au Chambeyron. - Compt. Rend. des séances de l'Acad. des Sciences, 230: 314-315; Paris.

Peltier, L. C. (1950): The geographic cycle in periglacial regions as it is related to climatic geomorphology. - Assoc. Am. Geogr. Annals. 40: 214 - 236.

Poser, H. (1932): Einige Untersuchungen zur Morphologie Ostgrönlands. - Medd. om Grønland, 94 (5), 55 pp.; Kopenhagen.

RAPP, A. (1960): Recent development of mountain slopes in Kärkevagge and surroundings, Northern Scandinavia. Geografiska Annaler, 42, 70-200; Stockholm.

- (1961): Studies of the postglacial development of mountain slopes. - Meddelanden fran Uppsala Universitets Geografiska Institution, Ser. A, Nr. 159, 11 p.; Uppsala.

- (1964): Recordings of mass wastings in the Scandinavian Mountains, - Zeitschr. f. Geomorph. Suppl. Bd. 5: 204-205; Berlin, Stuttgart.

RUDBERG, S. (1958): Some observations concerning mass movement on slopes in Sweden. - Geol. Fören. Stockholm, Förh. 80, 114 - 125; Stockholm.
- (1964): A report on some field observations concerning periglacial morphology and mass movement on slopes in Sweden. - Zeitschr. f. Geomorph. Suppl. Bd. 5, 192-203; Berlin, Stuttgart.

- (1962): A report on some field observations concerning periglacial morphology and mass movement on slopes in Sweden. - Biuletyn Peryglacjalny, 11: 311-323; Lódź.

- (1964): Slow mass movement processes and slope development in the Norra Storfjäll area, Southern Swedish Lappland. - Zeitschr. f. Geomorph., Suppl. Bd. 5: 192203; Berlin, Stuttgart.

SigafoOS, R. S. \& Hopkins, D. M. (1952): Soil instability on slopes in regions of perennially frozen ground. In: Frost action in soils: a symposium. - Natl. Acad. Sci., Natl. Research Council, Highway Research Board Spec. Rept. 2: $385 \mathrm{p}$.

SMITH, J. (1960): Cryoturbation data from South Georgia. Biuletyn Peryglacjalny 8: 73 - 79; Lódź.

Sørensen, T. (1935): Bodenformen und Pflanzendecke in Nordostgrönland. - Medd. om Gronland 93, 4: 69 S.; Kopenhagen.

SOUTADÉ, G. \& A. BAUDière (1970): Végétation et modelés des hauts versants septentrionaux de la Sierra Nevada. - Ann. de Géograph. 79: 709-736.

STOCKER, E. (1973): Bewegungsmessungen und Studien an Schrägterrassen an einem Hangausschnitt in der Kreuzeckgruppe (Kärnten). In: Beiträge zur Klimatologie, Meteorologie und Klimamorphologie. Festschrift für Hans Tollner zum 70. Geburtstag. - Arbeiten aus dem Geographischen Institut der Universität Salzburg, v. 3: 193-203; Salzburg.

Trolt, C. (1944): Strukturböden, Solifluktion und Frostklimate der Erde. - Klimaheft Geol. Rundschau 34: 545694; Stuttgart.

VeIT, H. (1988): Postglaziale Schwankungen der periglazialen Morphodynamik in den südlichen Hohen Tauern. Tagungsbericht und Wissenschaftliche Abhandlungen des 46. Deutschen Geographentages München 12. bis 16. Okt. 1987: 408-413; Wiesbaden.

WASHBURN, A. L. (1960): Instrumentation for mass wasting and patterned ground studies in Northeast Greenland. - Biuletyn Peryglacjalny 8: 59-64; Lódź.

- (1967): Instrumental observations of mass-wasting in the Mesters Vig district, Northeast Greenland. Medd. om Gronland, 166: 4 - 296; Kopenhagen.

- (1973): Periglacial processes and environments. 320 S.; Edward Arnold Ltd. Norwich.

- (1979): Geocryology. - London Edward Arnold.

Williams, P. J. (1957): Some investigations into solifluction features in Norway. - The Geographical Journal,123: 42-58; London.

- (1962): Quantitative investigations of soil movements in frozen ground phenomena. - Biuletyn Peryglacjalny, 11: 353-360; Lódź.

- (1966): Downslope soil movement at a subarctic location with regard to variations with depth. - Canadian Geotech. Journal 3: 191 - 203.

WORSLEY, P. \& HARRIS, C. (1974): Evidence for neoglacial solifluction at Okstindan, North Norway. - Arctic, v. 27: 128-144; Montreal.

YOUNG, A. (1960): Soil movement by denudational processes on slopes. - Nature, 188, 4785: 120-122.

Manuskript eingegangen am 25.1.1993 